\title{
A Numerical Fatigue Damage Model for Life Scatter of MEMS Devices
}

\author{
Behrooz Jalalahmadi, Farshid Sadeghi, Fellow, ASME, and Dimitrios Peroulis
}

\begin{abstract}
This paper presents a fatigue damage model to estimate fatigue lives of microelectromechanical systems (MEMS) devices and account for the effects of topological randomness of material microstructure. For this purpose, the damage mechanics modeling approach is incorporated into a new Voronoi finiteelement model (VFEM). The VFEM developed for this investigation is able to consider both intergranular crack initiation (debonding) and propagation stages. The model relates the fatigue life to a damage parameter " $D$ " which is a measure of the gradual material degradation under cyclic loading. The fatigue damage model is then used to investigate the effects of microstructure randomness on the fatigue of MEMS. In this paper, three different types of randomness are considered: 1) randomness in the microstructure due to random shapes and sizes of the material grains; 2) the randomness in the material properties considering a normally (Gaussian) distributed elastic modulus; and 3) the randomness in the material properties considering a normally distributed resistance stress, which is the experimentally determined material property controlling the ability of a material to resist the damage accumulation. Thirty-one numerical models of MEMS specimens are considered under cyclic axial and bending loading conditions. It is observed that the stress-life results obtained are in good agreement with the experimental study. The effects of material inhomogeneity and internal voids are numerically investigated.

[2009-0076]
\end{abstract}

Index Terms-Damage mechanics, fatigue behavior, material microstructure, microelectromechanical systems (MEMS) devices, numerical simulation.

\section{INTRODUCTION}

D URING THE past two decades, microelectromechanical systems (MEMS) have found growing applications (e.g., accelerometers [1], angular rate sensors [2], and RF MEMS switches and varactors [3]). As MEMS become more popular in electronic devices and their manufacturing processes improve, their size is reduced in order to improve their performance. Hence, they will be subject to higher deflections, stress levels, and frequencies. These operating conditions increase their probability of fatigue failures. These issues are attracting in-

Manuscript received January 2, 2009; revised May 26, 2009. First published July 28, 2009; current version published September 30, 2009. This work was supported in part by the Defense Advanced Research Projects Agency MEMS/NEMS S\&T Fundamentals Program and the IMPACT Center. Subject Editor D. L. DeVoe.

B. Jalalahmadi and F. Sadeghi are with the School of Mechanical Engineering, Purdue University, West Lafayette, IN 47907 USA (e-mail: bjalalah@ purdue.edu; Sadeghi@ecn.purdue.edu).

D. Peroulis is with the School of Electrical and Computer Engineering, Purdue University, West Lafayette, IN 47907 USA (e-mail: dperouli@ purdue.edu)

Color versions of one or more of the figures in this paper are available online at http://ieeexplore.iee.org.

Digital Object Identifier 10.1109/JMEMS.2009.2024800 creasing attention from researchers interested in fatigue behavior of MEMS devices.

Brown et al. [4] were among the first to introduce an electrostatically actuated fan-shaped test rig to test MEMS in fatigue. They showed that with increasing stress amplitude, number of cycles to fatigue decreased. Later, Muhlstein et al. [5] used finite-element method (FEM) to calculate the maximum stress in the same specimens as Brown et al. [4] did. They concluded that the life of polysilicon structures increases with decreasing stress amplitude. Kahn et al. [6] actuated a notched specimen with an array of electrostatic comb drives. They conducted a comprehensive series of tests and clearly demonstrated the increase in life with decrease in applied stress. In addition, they attributed the reduction in the nominal toughness under cyclic loading to subcritical growth of sharp cracks from the micromachined notches in the specimens. Kapels et al. [7] developed a thermal actuation test arrangement that permitted both monotonic loading and tension-tension fatigue testing. Again, although their lives were only up to one million cycles in contrast to the billion or more of the other two methods, their results showed the same trend as the previous findings. Connally and Brown [8] developed a resonant structure from single-crystal silicon that actuated a beam in out-of-plane deformation. They illustrated that as a crack grows, the resonant frequency decreases. They also postulated that static failure of the native surface silica layer is the mechanism for crack growth. Minoshima et al. [9] obtained fatigue lives ranging from less than 17 cycles to more than 50000 cycles for relatively large single crystal cantilever beams using a small electromagnetic actuator and a differential transformer displacement transducer. There have been other researchers investigating fatigue behavior of single crystal silicon or polysilicon (Ye et al. [10], Tsuchiya et al. [11], Fedder and Blanton [12], Bagdahn and Sharpe [13]). Sharpe and Bagdahn [14] reviewed the test devices developed by different research groups for polysilicon. Their comparison of different experimental data revealed a significant amount of scatter between the fatigue lives obtained by different groups. Kahn et al. [15] pointed out that among the fatigue mechanisms proposed for MEMS devices, the most likely candidate is one that involves mechanically induced damage as a result of cyclic stresses. Muhlstein et al. [16] studied the mechanisms for the delayed failure of 2- $\mu \mathrm{m}$-thick structural films of polycrystalline silicon under high-cycle fatigue loading conditions. They concluded that the mechanism of the apparent fatigue failure of thin-film silicon involves sequential oxidation and environmentally-assisted crack growth solely within the native $\mathrm{SiO}_{2}$ layer (reaction-layer fatigue mechanism).

Mohr et al. [17] used an electromagnetic actuator arrangement to subject bulk nickel to fully reversed bending fatigue stress. Their experiments led to stress-life (S-N) data for 
microstructures with critical dimensions greater than $10 \mu \mathrm{m}$ which were comparable to the data found in the literature for annealed and hardened nickel specimens. Dual et al. [18] determined the relationship between the decrease in resonant frequency and crack length using a structure consisting of a small specimen excited by a piezoelectric element. Buchheit et al. [19] investigated the effects of microstructure on the deformation and fatigue failure of the LIGA Ni MEMS devices. They obtained a fatigue limit of $200 \mathrm{MPa}$ which is about $40 \%$ of their measured tensile stress of $550 \mathrm{MPa}$. They also suggested a tie between microstructure and crack initiation, specifically in grains which have soft deformation directions oriented favorably with respect to the applied stress direction. Aktaa et al. [20] studied high cycle fatigue behavior of electrodeposited LIGA Ni structures using stress-controlled cyclic loading and fractography. Their fatigue results for LIGA Ni under fully reversed loading condition $(R=-1)$, predicted that the MEMS LIGA Ni behaved as the commercial pure bulk Ni. Their fractographical observations showed intergranular fatigue cracking which was explained by the predominantly ultrafine-crystalline microstructure of the LIGA Ni investigated. Allameh et al. [21] studied the effects of specimen thickness on S-N behavior and fatigue fracture modes in LIGA Ni MEMS structures. They concluded that the thinner $70-\mu \mathrm{m}$-thick structures had a higher endurance limits than the $270-\mu \mathrm{m}$-thick structures. In the case of the thinner structures, more extensive plastic deformation and stage II fatigue crack growth were observed. On the other hand, lower levels of plastic deformation were observed in the thicker structures along with corner crack nucleation, flat near-threshold fracture modes, and fatigue striations. Using a fixed-free cantilever beam subjected to fully reversed bending, Boyce et al. [22] found a ratio of endurance limit to ultimate tensile strength of $37 \%$ for LIGA Ni MEMS thin films. They suggested that fatigue cracks nucleate from oxide films which form on the surfaces of slip bands induced on the surfaces of cyclically deformed LIGA Ni microspecimens. Yang et al. [23] studied the mechanisms of fatigue in LIGA Ni MEMS thin films. They discovered that the mechanisms of crack nucleation and growth are the formation of slip bands and surface oxides, and crystallographic surface/subsurface crack nucleation and growth in the columnar grain structures. They also indicated that nanoscale grain films show surface and corner crack nucleations from preexisting defects. They confirmed that the thicker films have comparable fatigue life to annealed $\mathrm{Ni}$, while the thinner films have comparable fatigue life to wrought $\mathrm{Ni}$.

Fatigue mechanism, in general, consists of three stages: 1) crack initiation; 2) crack propagation; and 3) final catastrophic failure. Initial fatigue cracks occur at the microscale; therefore, in order to study their behavior accurately, the microstructure of materials needs to be taken into account. Miller [24] showed that the scatter in fatigue lives needs to be studied by considering the effect of material microstructure on early crack growth. Most of the materials are polycrystalline in nature and consist of grains with various crystallographic orientations, shapes, and sizes. Ito and Fuller [25] showed that grains of a polycrystalline material can be represented to a good degree of accuracy by using the Voronoi tessellation process. Zavattieri [26] and later, Zavattieri and Espinosa [27] showed that Voronoi polygons having random shapes and sizes can be used to simulate the grain structure of polycrystalline materials and its consequent effects on the fatigue life. Recently, using the Voronoi tessellation in a discrete element framework, Slack et al. [28] proposed a discrete damage mechanics model to study the fatigue of MEMS devices. They assumed that much of the fatigue life is spent in the initiation stage and therefore only considered this stage.

In this investigation, a Voronoi finite element (FE) fatigue damage model is developed to investigate the fatigue of MEMS devices and effects of topological randomness of MEMS material microstructure. For this purpose, damage mechanics approach developed by Kachanov [29], Robotnov [30], Chaboche [31], Memon et al. [32], and Slack et al. [28] is incorporated into a Voronoi finite element model (VFEM) developed by Jalalahmadi and Sadeghi [33]. The model developed for this investigation relates the fatigue life to a damage parameter $D$ which is a measure of the gradual material degradation under cyclic loading. Using the Voronoi FE framework gives the advantage and ability to calculate the deformation and stress distribution of domains with arbitrary microstructural topology. In addition, the current model considers both crack initiation and propagation stages, and concludes that much of the fatigue life is spent in the initiation stage, as described by Slack et al. [28]. In this investigation, 31 MEMS specimens with different microstructural distributions are considered under the cycling loading to estimate their fatigue lives and evaluate the scatter existing between the lives due to the different randomness sources. In addition, the effects of internal voids and inhomogeneous material properties on the fatigue lives are investigated. The results obtained from the VFEM indicate that the S-N curve obtained is in good agreement with the experimental results.

\section{Voronoi Finite-Element Modeling}

Suppose that a set of points is given in the plane [for example, dark points in Fig. 1(a)]. The number of points is assumed to be finite, and they are all distinct such that no points coincide in the plane. Considering this point set, every location in the plane is assigned to the closet member in the point set. If a location is equally close to two or more members of the point set, it is assigned to those members. Therefore, the set of locations assigned to each member in the point set forms its own region. The resulting regions are completely covering the plane because every location in the plane is included in at least one region. The set of locations assigned to two or more members in the point set forms the boundaries of the regions [lines in Fig. 1(a)]. Hence, the adjacent regions overlap only on their boundaries. Therefore, these regions form a tessellation because they are collectively covering every location of the plane, and they do not have common locations but their boundaries. This tessellation is referred to as the planar ordinary Voronoi tessellation or simply Voronoi diagram and the regions constituting the Voronoi diagram are called the Voronoi polygons or Voronoi cells. A general reference for the properties of Voronoi tessellation can be found in [34] and a more mathematical formulation in [35]. 


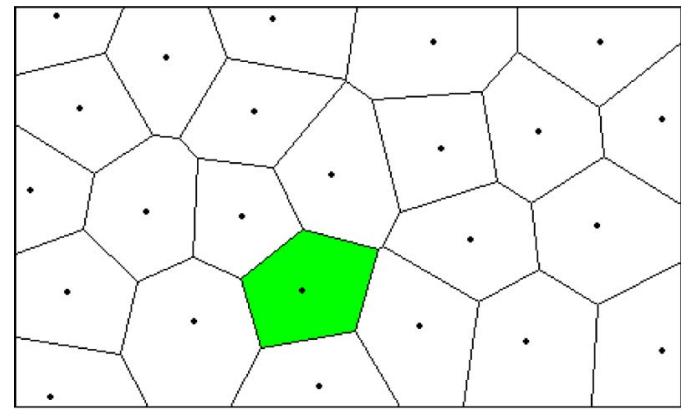

(a)

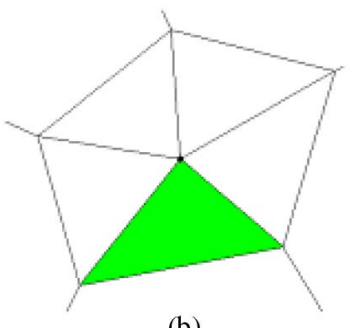

(b)

Fig. 1. (a) Discretizing a domain with the Voronoi elements. (b) Dividing a Voronoi element to finer triangular elements.

At microlevel, materials consist of grains which are random in size and shape. Ito and Fuller [25], Zavattieri and Espinosa [27], and Jalalahmadi and Sadeghi [33] showed that the Voronoi diagram can be used to simulate the topology of the material microstructure. Their reasoning for using the Voronoi diagram was that consider some random nucleation points in the crystallization process of a one-phase metal, if all grains start to grow simultaneously from these nucleation points at the same rate, microstructure produced will be in the form of a Voronoi diagram. Because of randomly chosen locations of the nucleation points, the grains can have random sizes. In VFEM, first, the domain is divided into Voronoi cells using the Voronoi tessellation, and then the geometrical center of each Voronoi element is determined. Since Voronoi elements are convex polygons, the center of each element is always located within the element. This property is used to divide the Voronoi element into finer triangular elements by connecting the nodes to the center. Fig. 1 shows the process of discretizing a domain into the Voronoi elements and then dividing a Voronoi element to finer triangular elements. A two-step assembly process is used to obtain the global stiffness matrix $(K)$. In the first step, assuming linear shape functions for each triangle, its stiffness matrix is obtained, and then the stiffness matrix for each Voronoi element can be set up using the stiffness matrices for each individual triangle. In the second step, the global $\mathrm{K}$ matrix is assembled using the stiffness matrices of the Voronoi elements. In VFEM, the strain energy method is used to extract the stiffness matrix for the triangular elements. For more detailed information about the VFEM, please refer to [33].

\section{FAtigue DAMAge Model}

Damage mechanics deals with the gradual degradation of materials which are subjected to loading. This deterioration includes the initiation, growth, and coalescence of microcracks or microvoids resulting to the initiation and growth of cracks [29]-[32]. The effects of damage on the mechanical response of a material have been recognized by employing a damage variable $D$ in the constitutive equations. In general, the damage variable is a tensor, but under the assumption of isotropic damage, it reduces to a scalar variable $D$. In order to define the 1-D damage parameter, Kachanov [29] considered a representative volume element (RVE) in a damage body under the uniaxial loading and found the most damaged plane perpendicular to the loading direction inside the RVE. Then, the damage variable was defined as

$$
D=\frac{\delta S_{D}}{\delta S}
$$

where $\delta S$ is the area of the intersection of the plane with the RVE, and $\delta S_{D}$ is the effective area of the intersections of all microcracks or microcavities which lie in $\delta S$. $D$ can range from 0 to 1 ; a value of zero means an undamaged material while the value of one corresponds to a completely damaged material resulting in complete loss of stiffness in tension that signifies crack initiation. Considering this definition of the damage variable, Rabotnov [30] defined the effective stress, $\tilde{\sigma}$, on the damaged material in tension

$$
\tilde{\sigma}=\frac{\sigma}{1-D}
$$

and in compression

$$
\tilde{\sigma}=\frac{\sigma}{1-h D}
$$

where $\sigma$ is the usual uniaxial stress in the undamaged material, $h$ is a crack closure parameter. In compression, $h$ is equal to one if the microcracks in the damaged material remain open. However, for most of the materials and loading conditions, the defects may close in compression. If the defects close completely, the area which effectively carries the load in compression is equal to the undamaged area. This means that $h$ is equal to zero. In practice, the real defects of complicated shapes do not close completely; hence, the crack closure parameter is introduced to account for this effect. The value of $h$ is one in tension (all of the microcracks open) and in compression $0 \leq h \leq 1$. The value of $h$ can be determined from the measurements of elasticity modulus in tension and in compression on a damaged material, as explained by Lemaitre [36]. Using a micromechanical model, Lemaitre [36] found out that the value of $h=0.2$ often gives results close to the experiments. In the current model, $h=1$ in tension and following Lemaitre [36] $h=0.2$ in compression. Regarding the effective stress defined, Lemaitre [36] defined the elasticity modulus of the damaged material as

$$
\tilde{E}=E(1-D)
$$

where $E$ is the elastic modulus of the undamaged material. Therefore, 1-D damaged coupled elasticity law takes the form

$$
\sigma=(1-D) E \varepsilon
$$




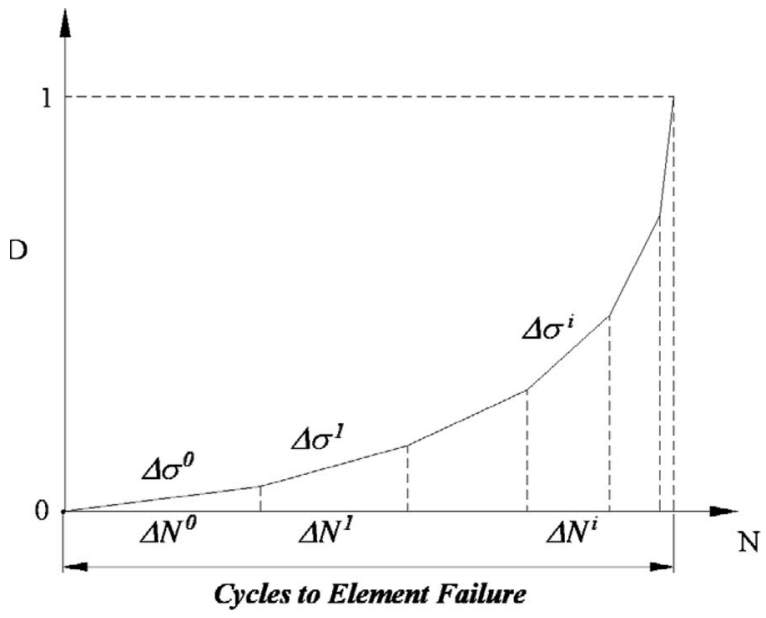

Fig. 2. Jump-in-cycles method. Damage evolution is assumed to be piecewise linear with respect to the number of cycles.

Constitutive equations for the damage accumulation have been formulated according to the underlying micromechanical damage mechanism. This mechanism is constrained to satisfy the laws of thermodynamics for fatigue damage, ductile damage, and creep damage [36]. In high cycle fatigue, a commonly used form for the evolution of $D$ is [37]-[40]

$$
\frac{d D}{d N}=\left[\frac{\sigma_{\mathrm{a}}}{\sigma_{\mathrm{r}}(1-D)}\right]^{m}
$$

where

$$
\sigma_{\mathrm{r}}=M_{0}\left(1-b \frac{\sigma_{\mathrm{m}}}{\sigma_{\mathrm{u}}}\right)
$$

where $N$ is the cycle number, $\sigma_{\mathrm{a}}$ and $\sigma_{\mathrm{m}}$ are the stress amplitude and mean stress (depend on loading conditions), respectively, and $M_{0}, b, m$, and $\sigma_{\mathrm{u}}$ (ultimate stress) are material properties that have to be experimentally identified. $M_{0}, b$, and $m$ are material dependent as described by Lemaitre [36], Xiao et al. [38], and Bolotin [40]. $\sigma_{\mathrm{r}}$ is called the resistance stress [40] since it is the parameter that controls the ability of a material to resist the damage accumulation. Note that $\sigma_{\mathrm{r}}$ which generally is a function of the mean stress would be equal to the constant value of $M_{0}$ if the material is loaded by a completely reversed stress field $\left(\sigma_{\mathrm{m}}=0\right)$. The damage variable is implemented within the current finite element modeling framework through affecting the elastic modulus of individual elements

$$
E=E_{0}(1-h D)
$$

where $E_{0}$ is the undamaged elastic modulus.

\section{NUMERICAL IMPLEMENTATION OF THE DAMAGED COUPLED EQUATIONS}

The fatigue analysis involves the simultaneous solution of the damage evolution (6), stiffness degradation (8), and constitutive equations for each element to account for the coupling between damage and the material constitutive behavior. Therefore, an iterative method was employed to solve the constitutive equa- tions and update the damage evolution in each element within the computational domain. Since simulations are conducted in the high cycles fatigue regime, it is computationally expensive to choose the iterative step length equal to one loading cycle. In order to overcome this problem, the procedure developed by Lemaitre [36], called the "jump-in-cycles" method, is employed here. The method assumes a piecewise periodic, constant amplitude loading, i.e., the stress field is assumed to remain unaltered over a finite number of cycles $\Delta N$ constituting a loading block $i$. During this loading block, the damage of each individual element can be assumed constant and equal to $D_{j}^{i}$, where $j$ is element number and $i$ indicates a block of cycles. Hence, the damage evolution is assumed to be piecewise linear with respect to the number of cycles, as shown in Fig. 2. However, it is to be noted that the shape of the damage evolution curve is not predefined, but it is an outcome of the numerical simulations due to the stress-damage coupling. In each loading block $i$, the material model and damage accumulation history obtained from the previous loading blocks are used to determine the current stress distribution in the domain. Knowing the stress amplitude for each element, its damage evolution rate can be calculated by

$$
\left(\frac{d D}{d N}\right)_{j}^{i}=\left[\frac{\left(\sigma_{\mathrm{a}}\right)_{j}^{i}}{\sigma_{\mathrm{r}}\left(1-D_{j}^{i}\right)}\right]^{m} .
$$

Note at the first loading block, $i=1$, damage is zero for all of the elements, $D_{j}^{1}=0$. After calculating the damage evolution rate for all elements, the maximum one is determined. This is the critical element in this loading block and determines the number of cycles $\Delta N^{i}$ spent in this loading block. The increment in damage $\Delta D$ is assumed to be constant over the block of cycles so the number of cycles in the current loading block is computed as

$$
\Delta N^{i}=\frac{\Delta D}{\left(\frac{d D}{d N}\right)_{\mathrm{crit}}^{i}}
$$

where

$$
\left(\frac{d D}{d N}\right)_{\mathrm{crit}}^{i}=\operatorname{Max}\left|\left(\frac{d D}{d N}\right)_{j}^{i}\right| .
$$

The total number of cycles is updated as

$$
N^{i+1}=N^{i}+\Delta N^{i} \text {. }
$$

Having the damage evolution rate for each element, its damage can be updated as

$$
D_{j}^{i+1}=D_{j}^{i}+\left(\frac{d D}{d N}\right)_{j}^{i} \Delta N^{i} .
$$

Now, the elastic modulus of each element should be updated according to the damage accumulated in that element, by

$$
E_{j}^{i}=E_{0}(1-h D)
$$

and the procedure is repeated for the next block of cycles. As previously mentioned, if the element is under tension, 


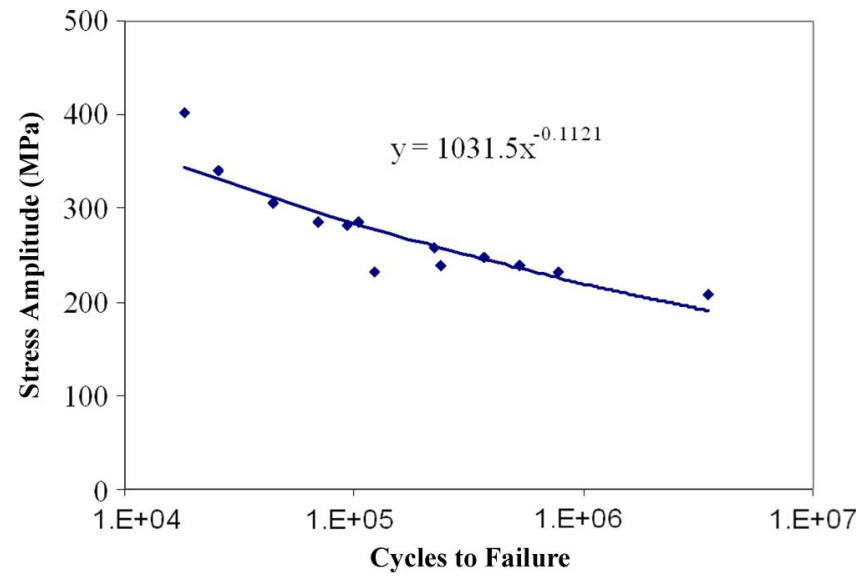

Fig. 3. S-N curve reported by Buchheit et al. [19] for LIGA Ni tensile specimens under the completely reversed loading condition along with a power law fit.

$h=1$, and if it is under compression, $h=0.2$. In addition, when damage becomes larger than one in some element, for subsequent calculations, the damage variable in that element is set to one and will not change further. This means the element loses the ability to support normal tensile loads, however, the element can still support compressive loads through crack closure effect $(h=0.2)$. The number of cycles spent for the first element to reach damage equal to one will be considered as the initiation life. Later, the failed elements, the ones with $D=1$, constitute a damaged zone. The crack propagation phase is modeled through joining the damaged zones which correspond to multiple microcracks coalescing together to form longer cracks.

\section{Evaluation of Material Fatigue DAMAGE PROPERTIES}

As described earlier, the damage evolution rate equation (6) introduces two new material parameters $\sigma_{\mathrm{r}}\left(=M_{0}\right.$, when $\left.\sigma_{\mathrm{m}}=0\right)$ and $m$ that have to be experimentally determined. One evaluation method for these parameters, employed here, is the use of experimental S-N data (S-N curve) available in literature. The general equation for an $\mathrm{S}-\mathrm{N}$ curve under completely reversed loading takes the form of a power law fit

$$
\sigma_{\mathrm{a}}=A N^{b}
$$

where $N$ is the number of cycles required to failure at the stress amplitude $\sigma_{\mathrm{a}}, A$ and $B$ are material constants. For this investigation, we use the fatigue data reported by Buchheit et al. [19] for LIGA Ni tensile specimens under the completely reversed loading condition. Fig. 3 shows their S-N data along with a power law fit, resulting

$$
A=1031.5 \mathrm{MPa} \quad b=-0.112 .
$$

Assuming the stress amplitude to be unchanged, (6) can be integrated from the undamaged condition to the fully damaged condition which corresponds to the fatigue life $N_{\mathrm{f}}$ at the stress

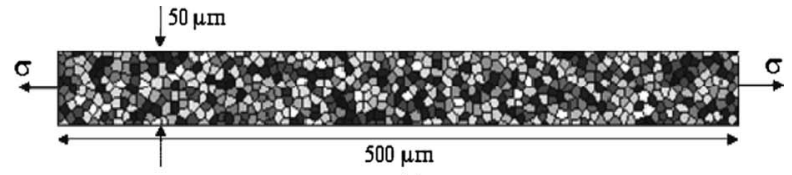

(a)

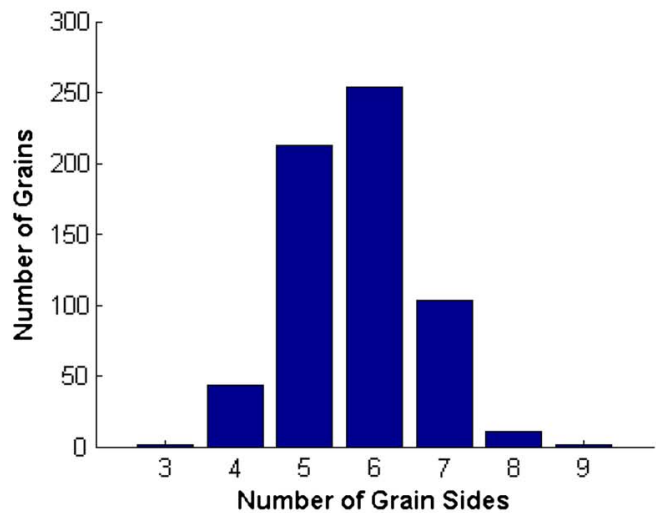

(b)

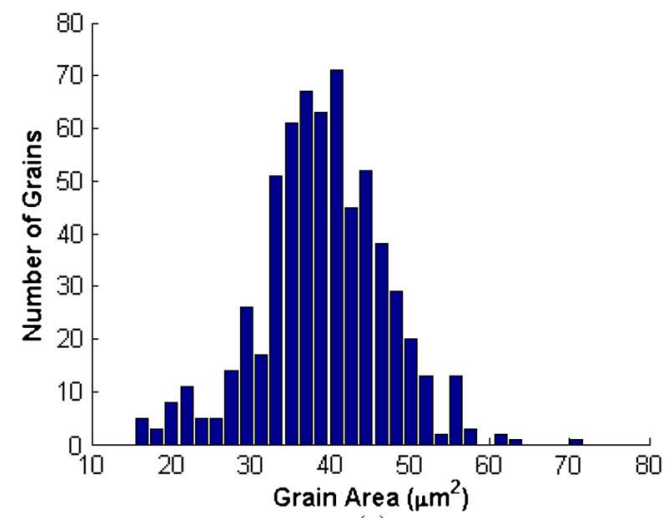

(c)

Fig. 4. (a) On dimensions of tensile specimens used in the numerical simulations. (b) Statistical distribution of number of sides of Voronoi elements in one of the generated specimens. (c) Statistical distribution of the Voronoi elements' area.

amplitude $\sigma_{\mathrm{a}}$. From (6) and considering that under the completely reversed loading condition $\sigma_{\mathrm{r}}=M_{0}$, it yields

$$
\begin{aligned}
\int_{0}^{N_{\mathrm{f}}} d N & =\int_{0}^{1}\left\{\frac{M_{0}(1-D)}{\sigma_{\mathrm{a}}}\right\}^{m} d D \Rightarrow N_{\mathrm{f}} \\
& =\left[\frac{M_{0}}{\sigma_{\mathrm{a}}}\right]^{m}\left(\frac{(1-D)^{m+1}}{-(m+1)}\right)_{0}^{1} \\
N_{\mathrm{f}} & =\frac{1}{(m+1)}\left[\frac{M_{0}}{\sigma_{\mathrm{a}}}\right]^{m} \Rightarrow \sigma_{\mathrm{a}} \\
& =\frac{M_{0}}{(m+1)^{\frac{1}{m}}} N_{\mathrm{f}}^{-\frac{1}{m}} .
\end{aligned}
$$

Comparison of (15) and (18) reveals

$$
-\frac{1}{m}=b \quad \frac{M_{0}}{(m+1)^{\frac{1}{m}}}=A
$$

or

$$
m=-\frac{1}{b} \quad M_{0}=A\left(1-\frac{1}{b}\right)^{-b} .
$$


TABLE I

NUMERICAL PARAMETERS USED FOR THE MEMS SPECIMENS UNDER THE CYCLIC AXIAL LOADING

\begin{tabular}{|l|c|}
\hline Beam length & $500 \mu \mathrm{m}$ \\
\hline Beam height & $50 \mu \mathrm{m}$ \\
\hline Average grain size & $5 \mu \mathrm{m}$ \\
\hline Elastic modulus $(E)$ & $175 \mathrm{GPa}$ \\
\hline Poisson's ratio $(v)$ & 0.3 \\
\hline Resistance stress $\left(\sigma_{r}\right)$ & $1334 \mathrm{MPa}$ \\
\hline Stress amplitude $\left(\sigma_{a}\right)$ & $350 \mathrm{MPa}$ \\
\hline
\end{tabular}

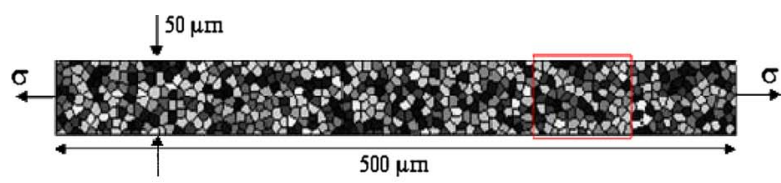

(a)

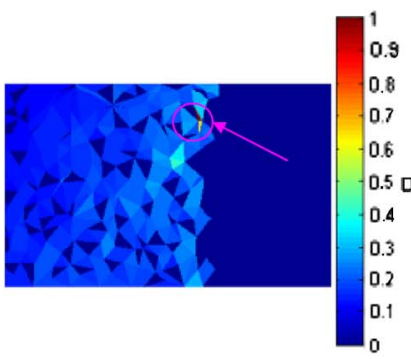

(b)

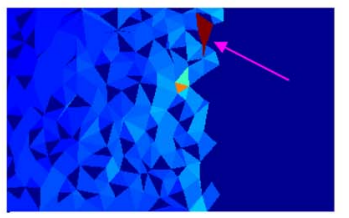

(c)

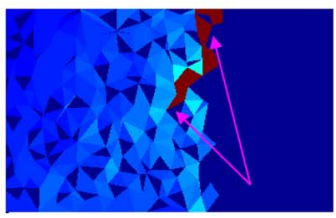

(d)

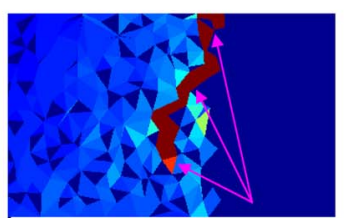

Fig. 5. Crack propagation (damage evolution) in the MEMS tensile specimen under the cyclic loading. (a) Initiation at $N=8708$ cycles. (b) $N=$ 8819 cycles. (c) $N=8934$ cycles. (d) Final failure at $N=8937$ cycles.

Substituting from (16), we have

$$
m=8.93 \quad \sigma_{\mathrm{r}}=M_{0}=1334 \mathrm{MPa} .
$$

\section{Application of the Fatigue Damage Model TO TENSILE MEMS SPECIMENS}

In this section, we apply the fatigue damage model developed in the previous sections to the MEMS beams subject to completely reversed axial loading condition. Since the depth (into the page) of the beam is small as compared to its height, we consider the problem as a 2-D plane stress problem. Here, the beam is $500 \mu \mathrm{m}$ in length and $50 \mu \mathrm{m}$ in height. Fig. 4(a) shows the beam modeled and used to examine the fatigue damage model.

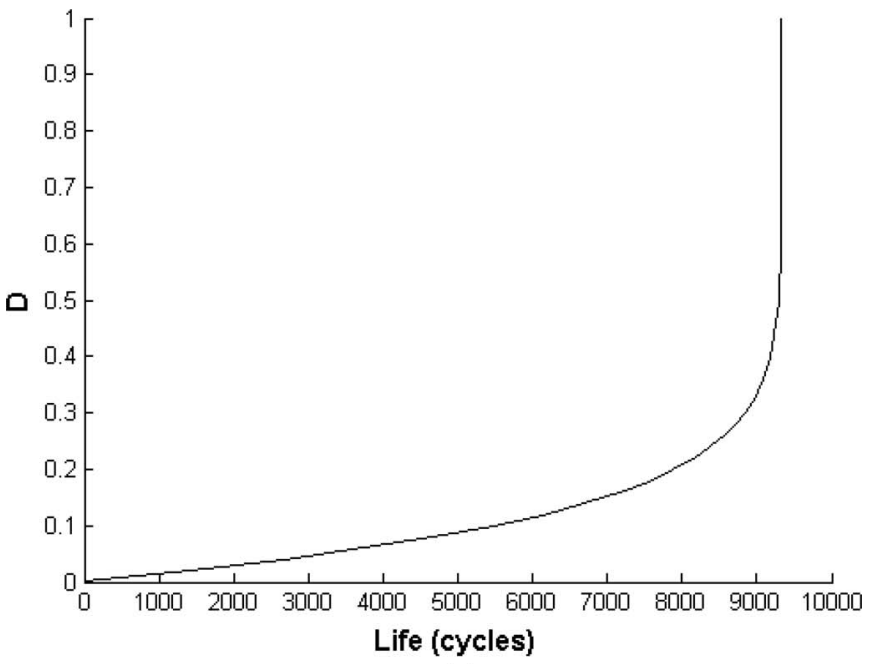

(a)

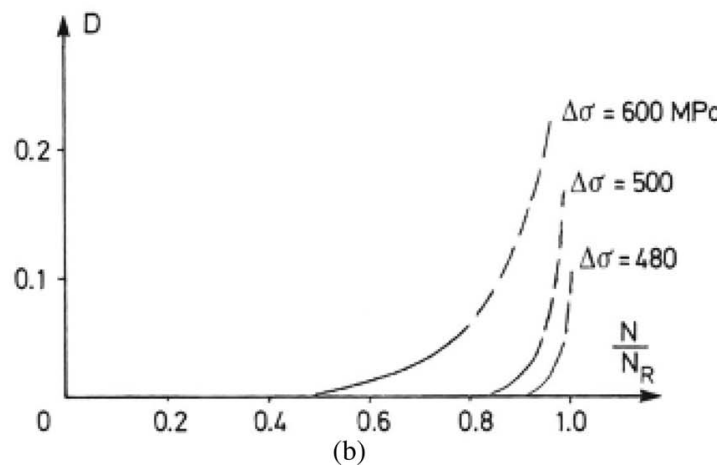

Fig. 6. (a) Damage evolution as a function of the number of cycles for the first failed element. (b) Experimental fatigue damage evolution of AISI 316 stainless steel.

Statistical distributions of number of sides of Voronoi elements and their areas are shown in Fig. 4(b) and (c), respectively, for the beam modeled. Voronoi tessellation results in a normal distribution of number of sides for Voronoi elements with most elements having five, six, or seven sides. As shown, distribution of the elements' area follows again a normal distribution for the generated domains. Ito and Fuller [25] similarly obtained the normal distributions for Voronoi elements' area and the number of element sides. Table I lists the numerical parameters employed in this investigation. In order to apply the desired axial loading condition on the specimen, the $x$-direction degrees of freedom on one end are fixed while the other end is moved in the $x$-direction (displacement controlled loading). Fig. 5 shows the damage evolution in the specimen including the failed elements, which are indicative of the crack propagation. The damage evolution as a function of the number of cycles for the first failed element is shown in Fig. 6(a). The damage evolution rate increases with increasing number of cycles indicating localization in the effective stress due to damage accumulation. This observation is in line with the experimental findings reported by Lemaitre [36] for fatigue damage evolution of AISI 316 stainless steel measured by means of elasticity changes, as shown in Fig. 6(b). Please note that Fig. 6 shows a qualitative comparison of the shape of two damage-life results. Hence, the damage-life results produced by the current model are qualitatively following the trend expected from Lemaitre [36]. 


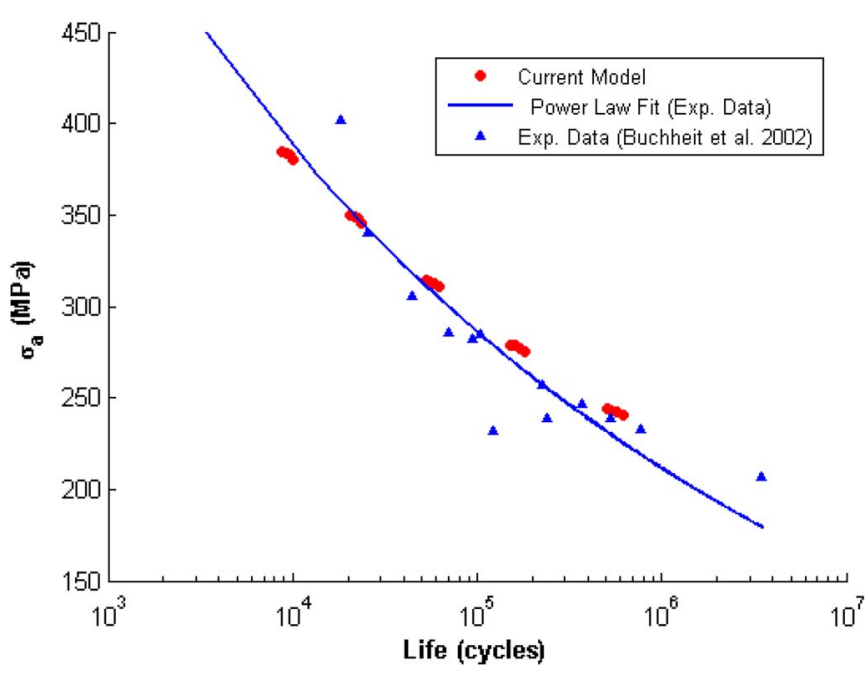

Fig. 7. Comparison of the results obtained for the MEMS specimens under the cyclic axial loading using the current model with the experimental S-N curve.

In order to validate the fatigue damage model developed with the experimental S-N data used, four specimens with identical dimensions and uniform material properties (Table I) but with different microstructural topology (different Voronoi distributions) are considered at different stress amplitudes $\left(\sigma_{\mathrm{a}}\right)$. Under the assumption of uniform material properties the only source of randomness is topological randomness due to the geometrical variations in the microstructure of specimens produced using the Voronoi tessellation process. Fig. 7 shows the fatigue lives obtained by the current model for the four specimens, each subjected to five different stress amplitudes, with the experimental data. This figure shows that there is a good agreement between the simulated and experimental results.

\section{A. Effect of Topological Material Disorder on Fatigue Life}

In order to investigate the effect of topological disorder of material microstructure on fatigue life, 31 specimens with different microstructural distribution were considered. The material properties for all 31 specimens are assumed to be homogenous and isotropic (Table I) so that the only difference between the specimens is the difference in microstructural topology. It should be noted that the difference in the microstructures is caused by different distributions of the Voronoi elements which have different sizes, shapes, areas, and orientations. When generating the different microstructures, only the average size of the Voronoi elements is controlled, and the random distributions of the elements' shapes, sizes, and orientations are outputs of Voronoi tessellation algorithm used to generate the domains. Fig. 8 shows the values of the maximum tensile stress $\left(\sigma_{x}\right)$ for the 31 different domains at the beginning of simulation when they are undamaged. As shown, they range from 347.9 to $367.2 \mathrm{MPa}$ with the average value of $354.8 \mathrm{MPa}$. This average value is slightly higher than the applied stress of $350 \mathrm{MPa}$ since we are considering the maximum tensile stress in each specimen and not the average tensile stress. It should be noted that the variation observed in the figure is caused by the microstructural topology disorders. Fig. 9 shows the values of the total fatigue lives as well as their fraction

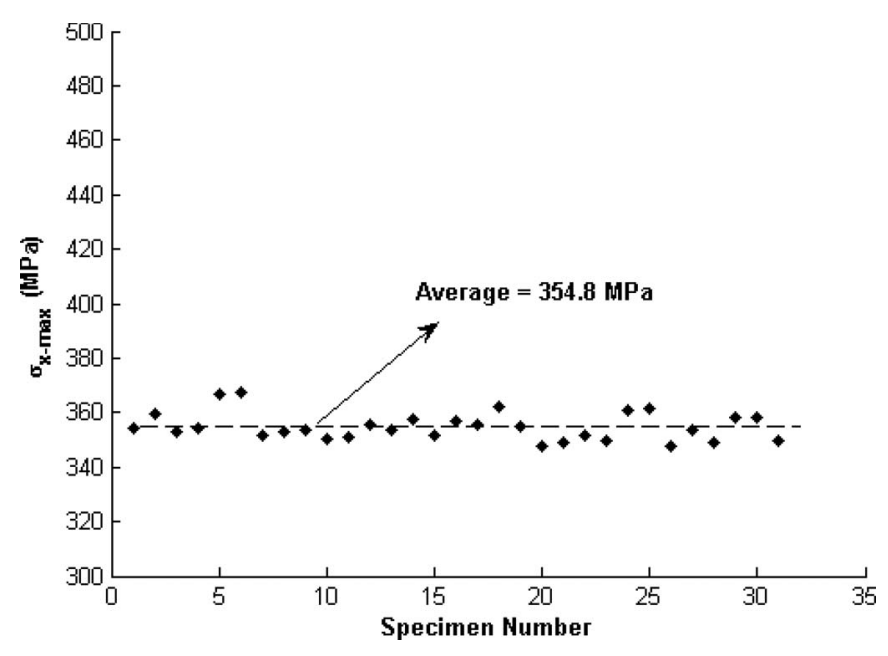

Fig. 8. Values of the maximum tensile stress $\left(\sigma_{x}\right)$ for the 31 different specimens under axial loading when they are still undamaged.

spent in the initiation stage for the 31 domains considered. As shown, in uniaxial loading most of the fatigue life is spent in the initiation stage. It can be explained with considering that there is a uniform stress field under the tensile loading, so once an element fails (crack initiates), the neighbor elements will fail shortly after that (the crack grows fast). This observation is in good agreement with Grandt [41] who showed in the case of high cycle fatigue much of the life is spent in the crack initiation stage.

In order to analyze the scatter existing between the results calculated here, we employ the two-parameter Weibull distribution plot. The slope of the Weibull distribution plot provides a scale of scatter of the data. For more information on the Weibull distribution, please refer to [42], [43]. Fig. 10(a) shows the scatter in initiation lives calculated from the current model. This indicates that the results follow a two-parameter Weibull plot with a slope of 20.19 and the Weibull strength, indicating the number of cycles for which the probability of failure is $63.2 \%$, of 9228 cycles. The Weibull plot for the total lives calculated here is shown in Fig. 10(b). The Weibull slope is 20.00 and the Weibull strength is 9527 cycles, as listed in Table II. The large values of the Weibull slope indicate that there is very little scatter in the uniaxial tension results. This can be attributed to the fact that in this part of investigation the material is assumed to be pristine with uniform material properties and no voids or flaws along the grain boundary.

\section{B. Effect of Material Inhomogeneity on Fatigue Life}

In this section, the approach used to introduce inhomogeneity in the material properties, and its effects on the fatigue lives are discussed. To take into account randomness of material properties in the microlevel, we assumed two different types of material inhomogeneity: 1) variation of elastic modulus between the different elements and 2) variation of resistance stress over the different elements.

Previously, we used the (undamaged) elastic modulus equal to $175 \mathrm{GPa}$ for all of the elements, but here, in order to introduce material inhomogeneity in the model, we employ 


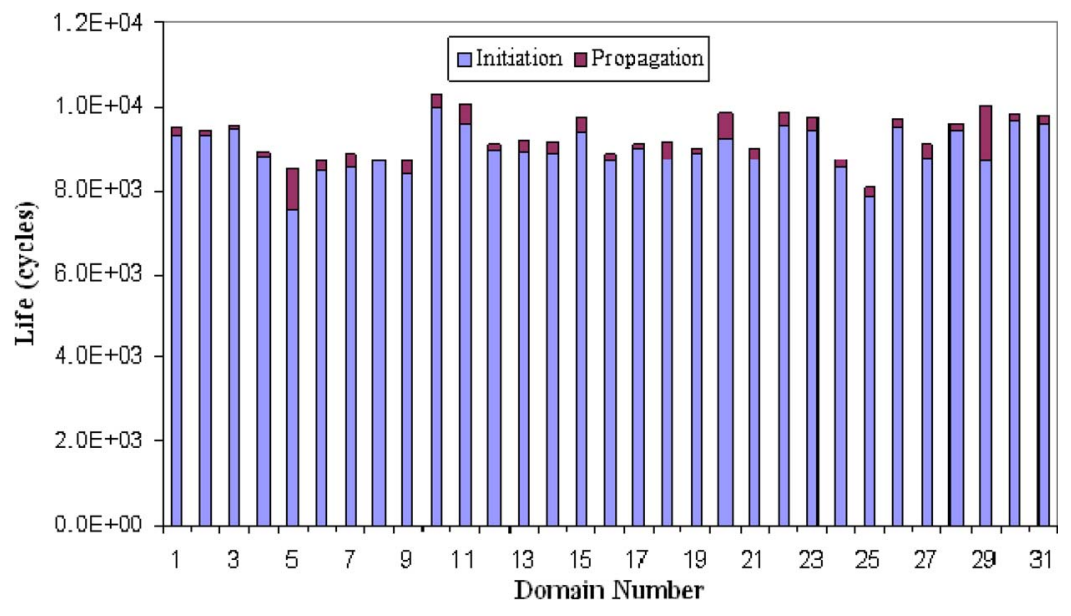

Fig. 9. Values of the initiation and propagation lives of the 31 specimens under the axial cyclic loading.

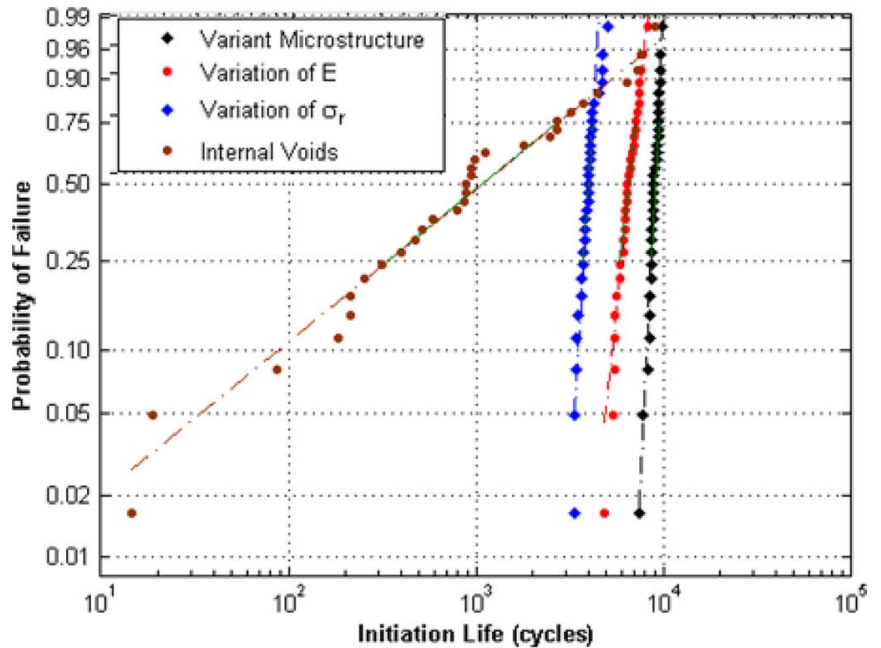

(a)

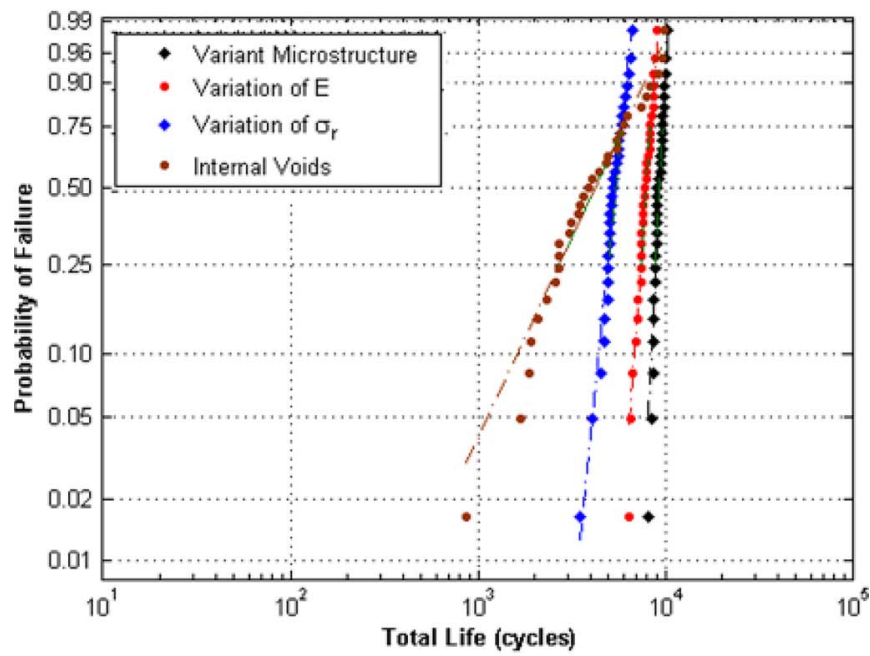

(b)

Fig. 10. Comparison of the Weibull distributions of (a) initiation lives, (b) total lives of the 31 MEMS specimens for cases of the same material properties, normal distribution of elastic modulus, normal distribution of resistance stress, and the internal voids.

the normal Gaussian distribution for the elastic modulus in each specimen with a variation of $10 \%$ about the average value of $175 \mathrm{GPa}$. It should be noted that the normal dis- tribution of elastic modulus assumed in this investigation is used simply as a modeling tool to incorporate randomness of material properties at the microstructural level, (i.e., elastic anisotropy and material defects). Fig. 11(a) shows the normal distribution of the elastic modulus employed for studying the effects of inhomogeneity on the stress distribution and the fatigue life of specimen 1. Using the different normal distribution of the elastic modulus for each numerical domain, the maximum tensile stresses shown in Fig. 11(b) are obtained for the 31 considered specimens while they are undamaged. For comparison purposes, this figure also shows the results obtained for the same specimens with using the uniform elastic modulus. The average value of maximum tensile stress $\left(\sigma_{\max }\right)$ calculated with using the inhomogeneous elastic modulus is 385.2 $\mathrm{MPa}$ which is larger than the average value of $354.8 \mathrm{MPa}$ obtained from the specimens having the uniform elastic modulus. This indicates that introducing inhomogeneity causes $\sigma_{\max }$ to increase because adjacent elements having different elastic modulus interact with each other and create some local stress concentrations. The Weibull plots of the initiation and total lives of the 31 specimens obtained using the normal distribution of elastic modulus are also shown in Fig. 10(a) and (b), respectively. In addition, Table II lists the Weibull slopes and strengths obtained. As expected, the values of both the Weibull slope and strength obtained using the inhomogeneous elastic modulus is lower than the ones calculated using the uniform elastic modulus, which is similar to the results of Slack et al. [28]. The Weibull slope of initiation lives of the specimens with inhomogeneous elastic modulus is equal to 8.77 which is significantly lower than the value 20.19 obtained for the uniform elastic properties. Considering total lives, the Weibull slope for the uniform elastic modulus reduces from 19.99 to 13.68 for the normally distributed the elastic modulus. Therefore, when the elastic modulus is varied, a new randomness is introduced in addition to the randomness caused by the microstructure. This consequently reduces the fatigue lives and increases their scatter compared with the homogeneous property condition.

Now, we keep all the material properties uniform as in the previous section except the resistance stress. Instead of uniform resistance stress equal to $1334 \mathrm{MPa}$ for all of the elements, 
TABLE II

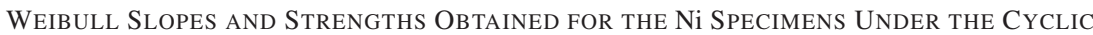
AXIAL LOADING FOR THE DifFERENT SimUlation CONDITIONS

\begin{tabular}{|l|c|c|c|c|}
\hline \multirow{2}{*}{ Simulation Condition } & \multicolumn{2}{|c|}{ Initiation life } & \multicolumn{2}{c|}{ Total life } \\
\cline { 2 - 5 } & Weibull Slope "e" & $\begin{array}{c}\text { Weibull } \\
\text { Strength } \\
\text { (cycles) }\end{array}$ & Weibull Slope "e" & $\begin{array}{c}\text { Weibull } \\
\text { Strength } \\
\text { (cycles) }\end{array}$ \\
\hline Homogeneous & 20.19 & 9228 & 20.00 & 9527 \\
\hline $\begin{array}{l}\text { Variation of elastic } \\
\text { modulus }(E)\end{array}$ & 8.77 & 6920 & 13.68 & 8153 \\
\hline $\begin{array}{l}\text { Variation of resistance } \\
\text { stress }\left(\sigma_{r}\right)\end{array}$ & 9.61 & 4200 & 8.65 & 5672 \\
\hline One internal void & 0.77 & 1732 & 1.99 & 5219 \\
\hline
\end{tabular}

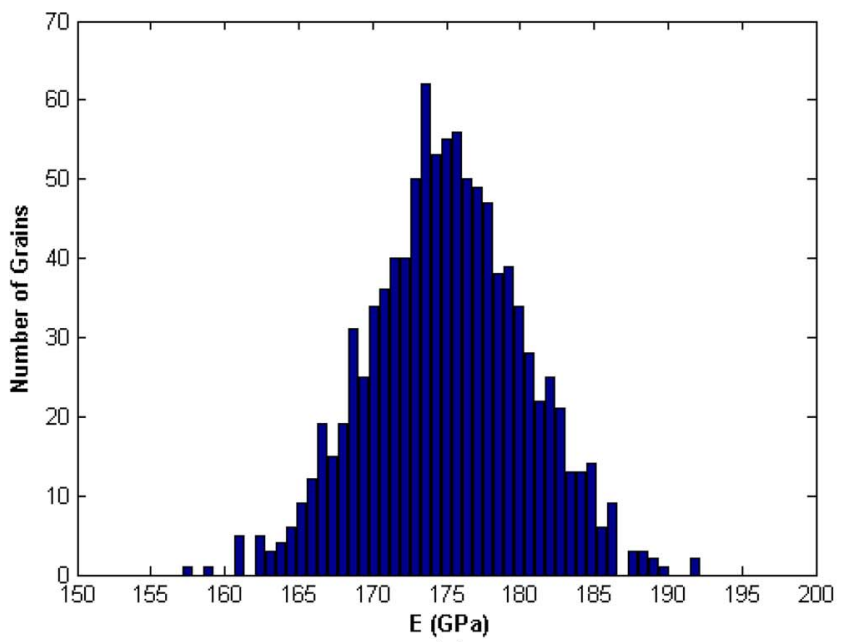

(a)

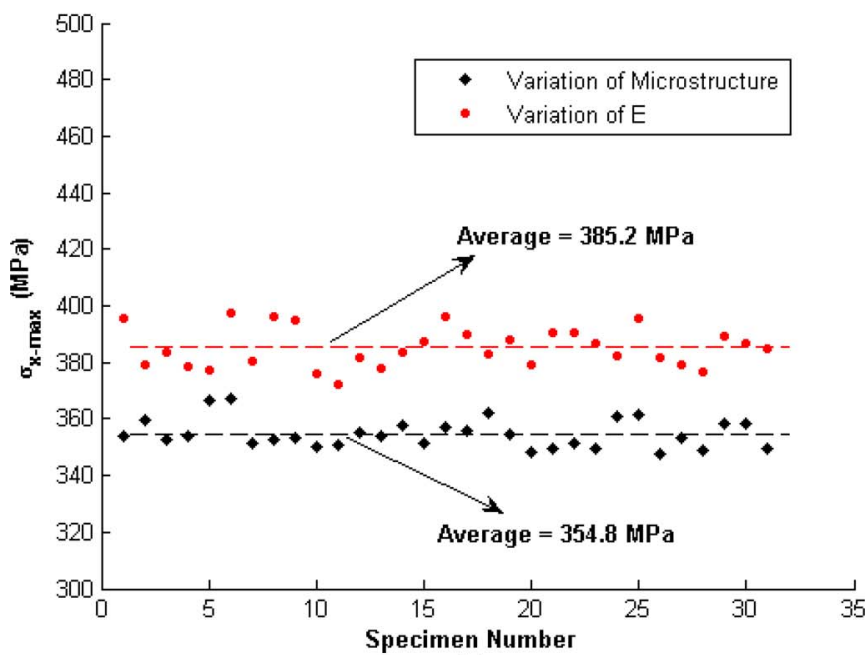

(b)

Fig. 11. (a) Normal distribution of the elastic modulus employed for the specimen 1 with $10 \%$ variation of the average value of $175 \mathrm{GPa}$. (b) Values of the maximum tensile stress obtained for the 31 specimens with the different microstructures using the uniform elastic modulus and its normal distribution.

a normal Gaussian distribution of the resistance stress with a variation of $10 \%$ about the average value of $1334 \mathrm{MPa}$ is used for each specimen; the one used for specimen 1 is shown in Fig. 12. It should be mentioned that there is no need to compare the values of maximum tensile stress obtained in this part of investigation at the commencement of simulation for

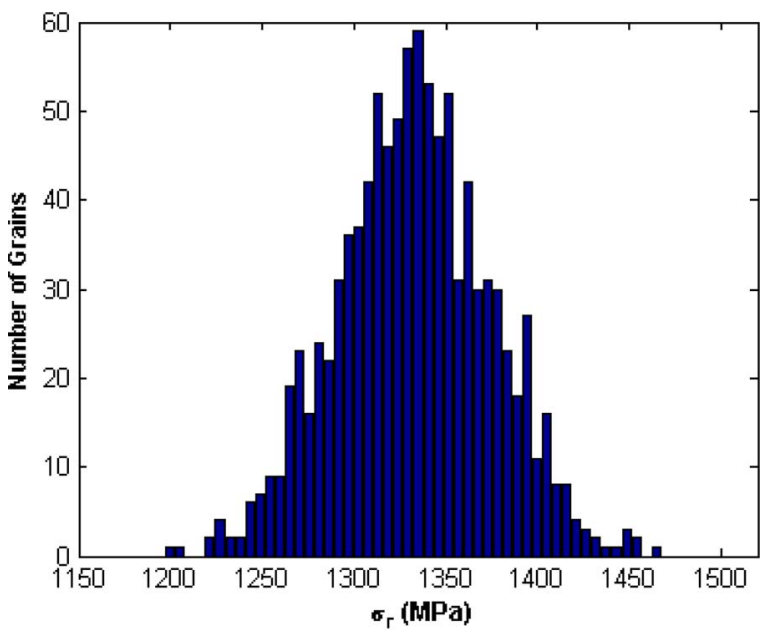

Fig. 12. Normal distribution of the resistance stress applied to the specimen 1 with $10 \%$ variation of the average value of $1334 \mathrm{MPa}$.

the undamaged specimens with the values obtained for the homogeneous undamaged specimens since they are exactly same. The reason can be understood by remembering that the resistance stress is a fatigue parameter which enters to the computations after the first loading cycle and does not affect the behavior of undamaged specimens. In addition, Fig. 10(a) and (b) shows the Weibull plots of the initiation and total lives of the 31 specimens obtained in this part of investigation. The Weibull slope of initiation lives of the specimens with the inhomogeneous resistance stress is equal to 9.61, and their Weibull strength is 4200 cycles. For total lives, we obtain the Weibull slope equal to 8.65 and the Weibull strength equal to 5671 cycles. As observed, again the values of both the Weibull slope and strength obtained using the inhomogeneous material properties is lower than the ones calculated using the homogeneous property condition. Hence, again, the variation of resistance stress is another randomness causing the reduction of the fatigue lives and the increase of their scatter compared with the homogeneous property condition. Table II summarizes the results obtained throughout this section. It should be noted that there is a larger reduction in fatigue lives and more scatter between them using the variation of resistance stress than using the variation of elastic modulus. This larger effect of resistance stress on the fatigue life can be explained by the fact that the resistance stress variable is related directly to the fatigue strength of the elements and is explicitly included in (6). 

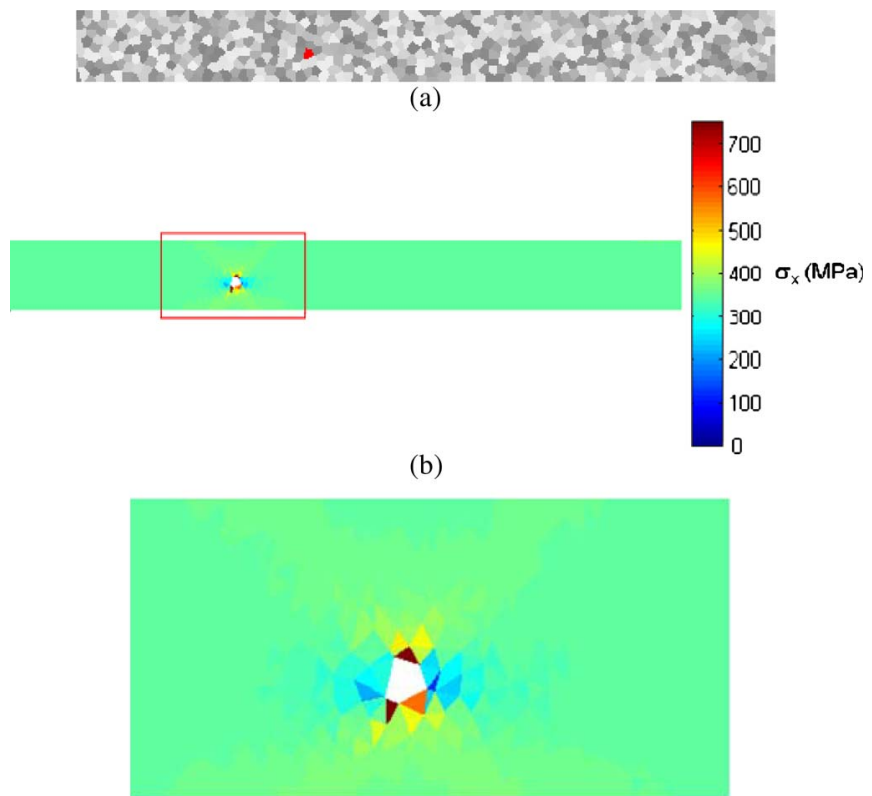

(c)

Fig. 13. (a) Initial void introduced to specimen 1. (b) Stress distribution around the void (applied stress is equal to $350 \mathrm{MPa}$ ). (c) Magnified view.

\section{Effect of Internal Voids on Fatigue Life}

The effects of initial internal voids on fatigue life are discussed in this section. In order to be able to compare the results obtained for the flawless domains and the ones obtained for the domains having the initial voids, the same 31 specimens previously generated are used again. One internal void is distributed randomly inside the domains at the beginning of simulations to investigate the effects of initial internal voids on fatigue life. This is implemented in the model by randomly removing one Voronoi element from each domain. Considering the average size of element sides $(5 \mu \mathrm{m})$, the average size of void sides is $5 \mu \mathrm{m}$ as well. However, because of different microstructural distributions, the exact size, location, and orientation of these internal voids vary among different domains which cause additional randomness in domains creating more scatter in the obtained fatigue lives. Fig. 13(a) shows one initial internal void introduced to specimen 1 . The axial stress distribution influenced by this internal void is shown in Fig. 13(b) and (c). As expected, the void acts as the internal source for stress concentration. In order to obtain a better understanding of how the internal voids can affect the crack propagation, Fig. 14 shows a comparison between the crack paths developed in specimen 1 in presence and absence of the internal void. As shown, when there is a void in the material, fatigue crack nucleates and grows near to this weak point, which agrees with the fatigue experimental studies [41].

The values of maximum tensile stresses for the 31 specimens with and without internal voids are shown in Fig. 15. As observed, the influences of the internal voids on the maximum tensile stress are significantly different between different specimens caused by the random nature of internal voids simulated here by their random size, location and orientation, as indicated before. While in some cases, the internal void does not change the value of maximum $\sigma_{x}$, it increases the maximum stress

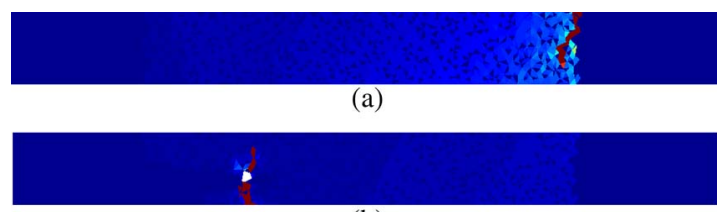

(b)

Fig. 14. Influence of the internal void on the crack propagation path. (a) Crack path in the specimen 1 without any void. (b) Crack path in the specimen 1 having an internal void.

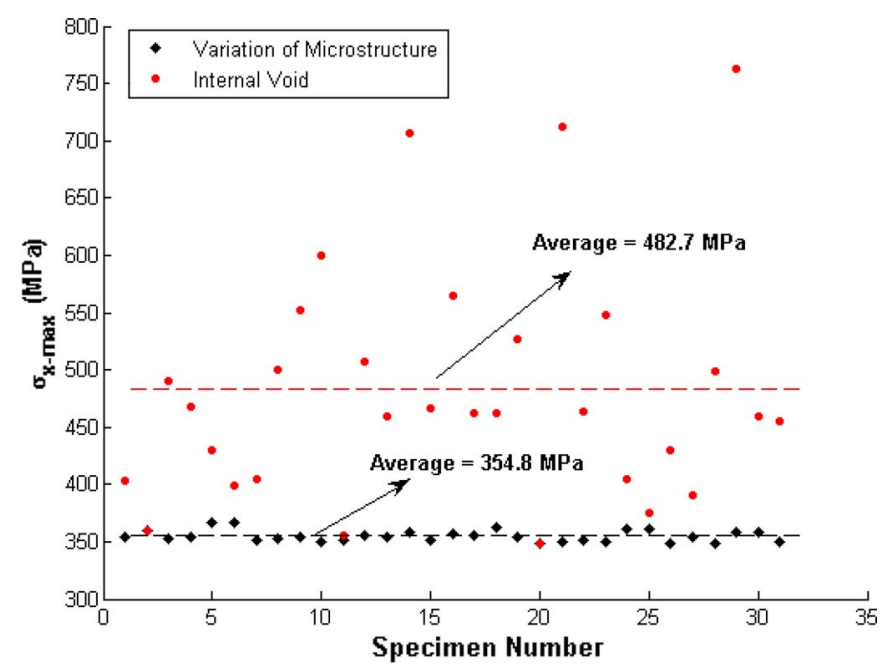

Fig. 15. Comparison of values of the maximum tensile stress obtained using the 31 specimens with two internal voids and no internal voids.

TABLE III

Numerical Parameters USED For the MEMS SPECIMENS UNDER THE CYCLIC BENDING LOADING

\begin{tabular}{|l|c|}
\hline Beam length & $500 \mu \mathrm{m}$ \\
\hline Beam height & $50 \mu \mathrm{m}$ \\
\hline Average grain size & $5 \mu \mathrm{m}$ \\
\hline Elastic modulus $(E)$ & $175 \mathrm{GPa}$ \\
\hline Poisson's ratio $(v)$ & 0.3 \\
\hline Resistance stress $\left(\sigma_{r}\right)$ & $1334 \mathrm{MPa}$ \\
\hline Stress amplitude $\left(\sigma_{a}\right)$ & $315 \mathrm{MPa}$ \\
\hline
\end{tabular}

more than twice in some specimens. Overall, the average value of $\sigma_{\max }$ increases significantly from 354.8 to $482.7 \mathrm{MPa}$ when the internal voids are introduced. The Weibull plots for the initiation and total lives calculated using the domains including the internal voids are shown in Fig. 10(a) and (b), respectively. The slope of total lives distribution reduces from 20.00 to 1.99 , and its Weibull strength decreases to 5219 cycles. Considering the initiation lives, the effects of the internal voids are still more noticeable, the Weibull slope is 0.77 , and the strength decreases from 9228 cycles to 1732 cycles. As expected, the introduction of the internal voids decreases dramatically the fatigue lives and increases their scatter, as observed by Slack et al. [28]. Table II summarizes the results obtained in this section.

\section{Application of the Fatigue Damage Model TO MEMS CANTILEVER BEAMS}

Here, we apply the fatigue damage model developed to the MEMS cantilever beams under the completely reversed 


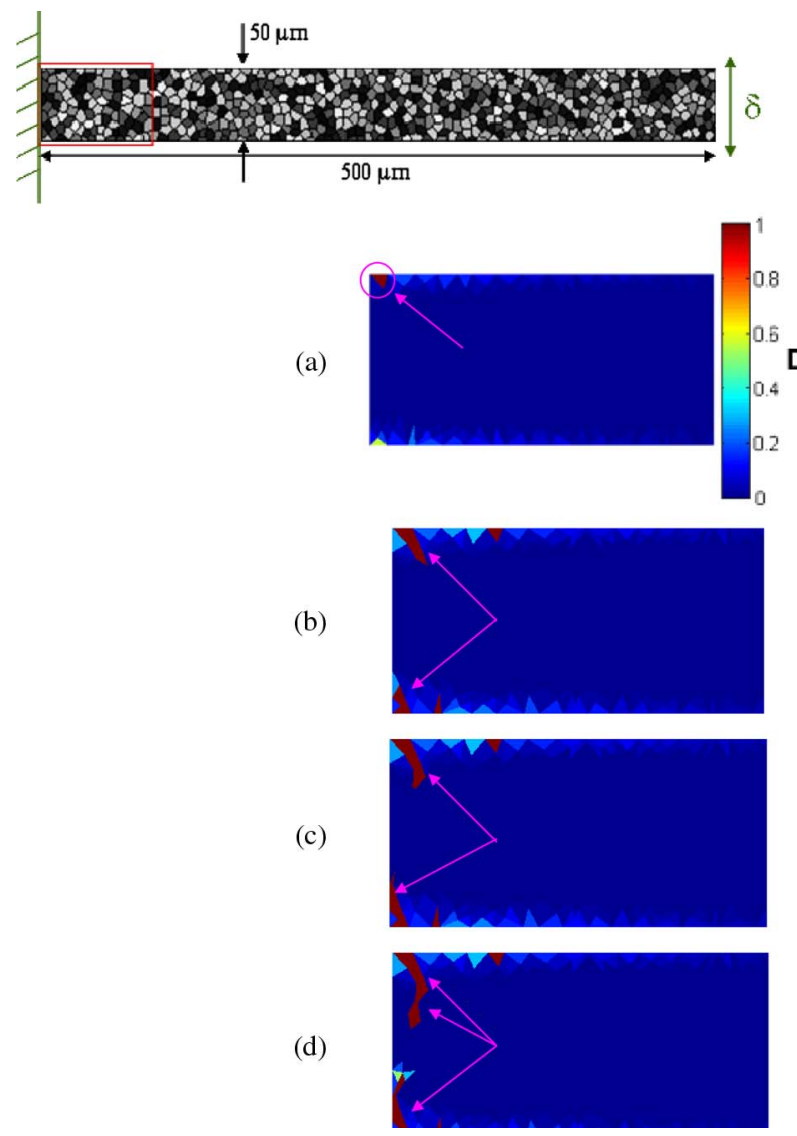

Fig. 16. Crack propagation (damage evolution) in the MEMS specimen under the cyclic bending loading. (a) Initiation at $N=80239$ cycles. (b) $N=120088$ cycles. (c) $N=121418$ cycles. (d) Final failure at $N=$ 122306 cycles.

bending loading. In order to model the cantilever beams, we consider the 31 specimens created in the previous section however, subject to bending instead of axial loading. The beams are again $500 \mu \mathrm{m}$ long and $50 \mu \mathrm{m}$ thick [Fig. 4(a)]. Table III lists the numerical parameters employed in this part of investigation. In order to model the desired bending condition on the specimen, the degrees of freedom on one end are completely fixed while the other end is moved in the $y$-direction (displacement controlled loading). Fig. 16 shows the crack path for completely damaged elements for specimen 1 . It should be noted in the case of axial loading, fatigue crack can start some point along the beam which has a weak microstructure (Fig. 5) since in this case all the points experience a theoretically the same stress. However, because there is nonuniform stress field in the case of cantilever beam, higher stresses are generated close to the fixed end. In addition, cracks generally start close to this fixed end as shown in Fig. 16.

Next, we consider the same four specimens, considered in previous section, under the cyclic bending loading to obtain S-N data using the fatigue damage model developed and compare them with the experimental results. The comparison of the experimental data and the initiation and total lives obtained using the current model is shown in Fig. 17. As shown, the initiation lives obtained agree well with the experimental results as well as with the fatigue lives obtained for the same specimens under the cyclic axial loading (Fig. 7). However, the total

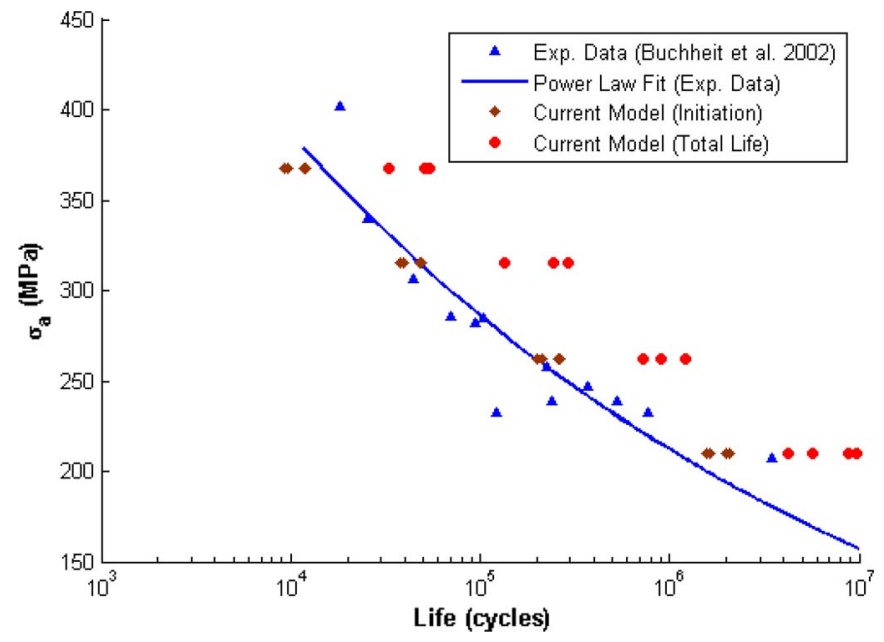

Fig. 17. Comparison of the results obtained for the MEMS specimens under the cyclic bending loading using the current model with the experimental S-N curve.

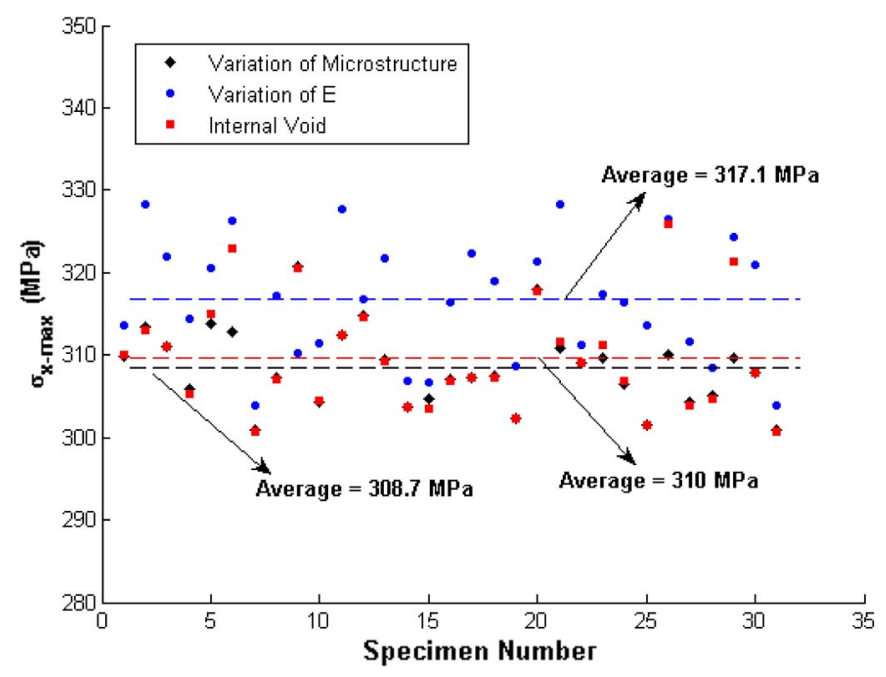

Fig. 18. Comparison of values of the maximum tensile stress obtained using the 31 MEMS specimens under the cyclic bending loading for cases of the same material properties, normal distribution of elastic modulus, and the internal voids.

lives predicted are slightly higher than the experimental values. This observation can be explained by considering the different stress gradients resulting from axial and bending loads. An axial push-pull specimen has a uniform stress over the specimen cross section, whereas a bending specimen sees a tensile stress on one side of the specimen, a compressive stress on the opposite side, and zero stress at the neutral axis. Thus, a bend specimen with the same dimensions as an axially loaded specimen and subjected to the same peak cyclic stress actually has a smaller volume of highly stressed material and by the weakest link concept often has a longer fatigue life [44]-[47].

\section{A. Effect of Topological Disorder on Fatigue Life}

Fig. 18 shows the values of the maximum tensile stress $\left(\sigma_{x}\right)$ for the 31 different domains, generated in the previous section, under the first completely reversed bending loading cycle, i.e., when they are undamaged. As a conclusion of different 


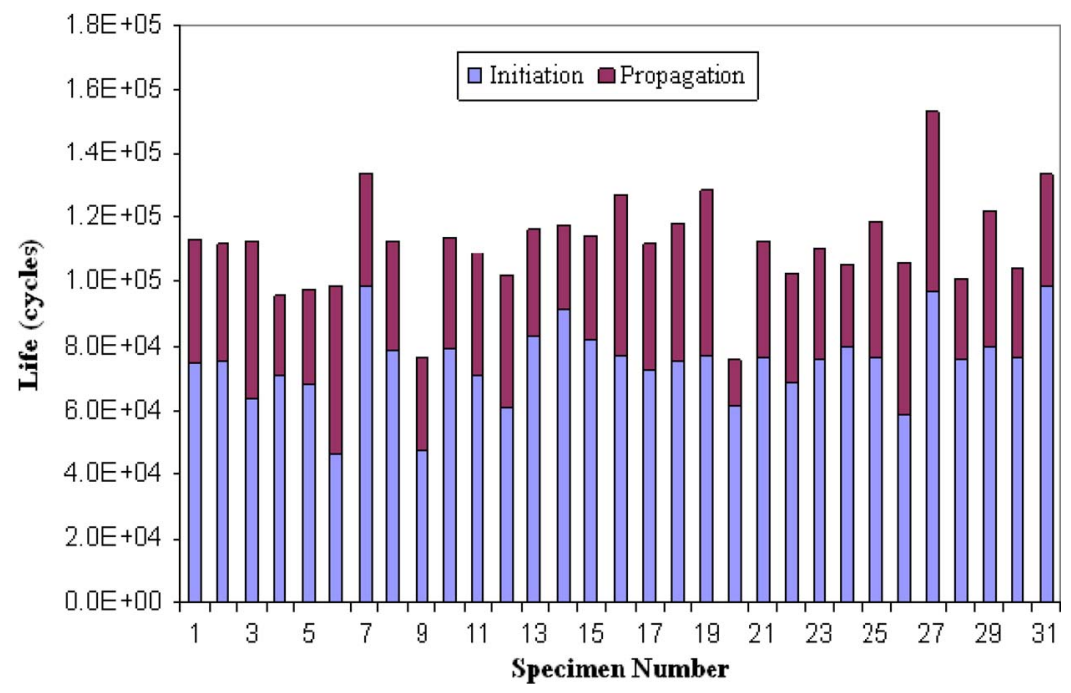

Fig. 19. Values of the initiation and propagation lives of the 31 specimens under the cyclic bending loading.

microstructural topologies, the maximum tensile stresses range from 300.9 to $320.7 \mathrm{MPa}$ with an average value of $308.7 \mathrm{MPa}$. As previously mentioned, we employ displacement controlled loading. The theoretical maximum stress in the cantilever beams corresponding to the applied displacement should be $315 \mathrm{MPa}$. As noted, the average value obtained here is in good agreement with the theoretical one. Again, it should be noted that the variation observed in the figure is caused by the microstructural topological disorders. The total fatigue lives obtained here for different 31 specimens as well as their fraction spent in the initiation stage are shown in Fig. 19. Again much of the life is spent in the initiation stage but not as much as the initiation fraction in the uniaxial loading condition. This less initiation fraction is due to the nonuniform stress field existing in the bending case unlike with the uniform stress field existing in the uniaxial loading, as mentioned in the literature [44]-[47]. The Weibull distribution of the initiation and total lives calculated for the 31 specimens are shown in Fig. 20(a) and (b), respectively. A Weibull slope of 7.12 and the Weibull strength of 78679 cycles is obtained for the initiation lives, and for the total lives the slope is 7.54 and the strength is 117210 cycles. It is noted that the Weibull slopes obtained here for the homogeneous specimens under the bending loading are smaller than the ones obtained for the same specimens under the uniaxial loading in the previous section. Again, this higher scatter can be related to the nonuniform stress distribution, which magnifies the effects of microstructural topology, existing in the specimens under the bending loading.

\section{B. Effect of Material Inhomogeneity and Internal Voids on Fatigue Life}

Now, in order to study the effects of material imperfection on the fatigue lives of MEMS cantilever beams, we consider three different sources of additional randomness introduced in the previous section. These sources are the following: 1) normal distribution of elastic modulus with a variation of $10 \%$ about the average value of $175 \mathrm{GPa}$;

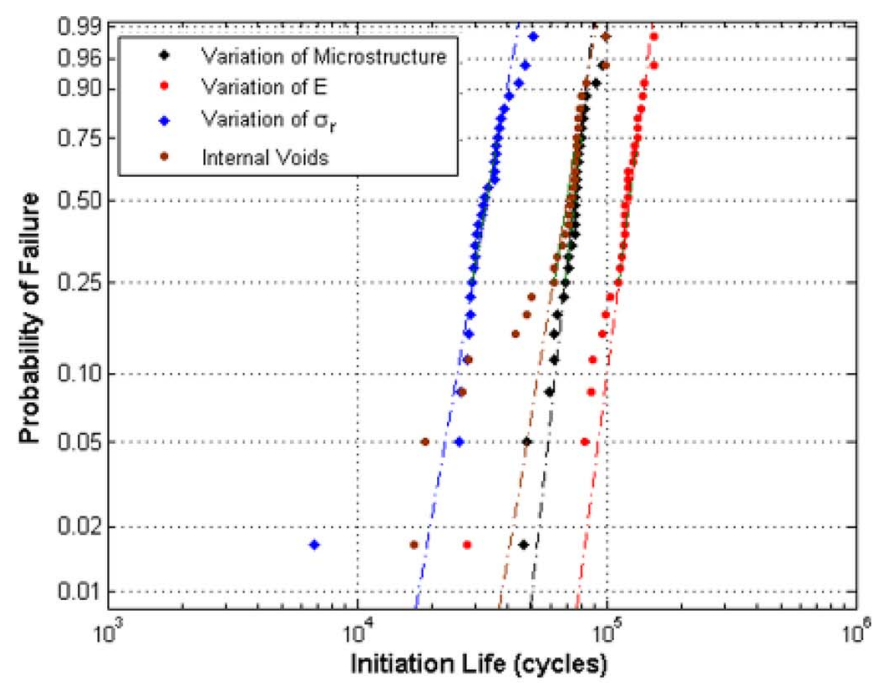

(a)

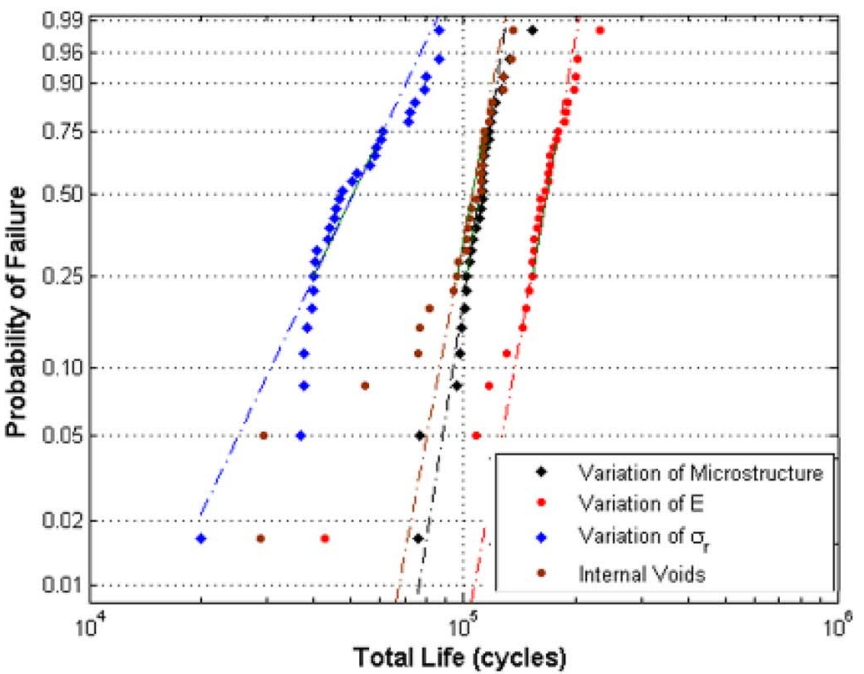

(b)

Fig. 20. Comparison of the Weibull distributions of (a) initiation lives, (b) total lives of the $31 \mathrm{Ni}$ MEMS specimens under the cyclic bending loading for cases of the same material properties, normal distribution of elastic modulus, normal distribution of resistance stress, and the internal voids. 
TABLE IV

Weibull Slopes and Strengths Obtained for the Ni Specimens Under the CyClic Bending LOADING FOR THE DIFFERENT SIMULATION CONDITIONS

\begin{tabular}{|l|c|c|c|c|}
\hline \multirow{2}{*}{ Simulation Condition } & \multicolumn{2}{|c|}{ Initiation life } & \multicolumn{2}{c|}{ Total life } \\
\cline { 2 - 5 } & Weibull Slope "e" & $\begin{array}{c}\text { Weibull } \\
\text { Strength } \\
\text { (cycles) }\end{array}$ & Weibull Slope "e" & $\begin{array}{c}\text { Weibull } \\
\text { Strength } \\
\text { (cycles) }\end{array}$ \\
\hline Homogeneous & 7.12 & 78679 & 7.54 & 117210 \\
\hline $\begin{array}{l}\text { Variation of elastic } \\
\text { modulus }(E)\end{array}$ & 6.24 & 126050 & 5.90 & 174410 \\
\hline $\begin{array}{l}\text { Variation of resistance } \\
\text { stress }\left(\sigma_{r}\right)\end{array}$ & 4.72 & 35917 & 3.43 & 58930 \\
\hline One internal void & 3.86 & 72188 & 5.18 & 110130 \\
\hline
\end{tabular}

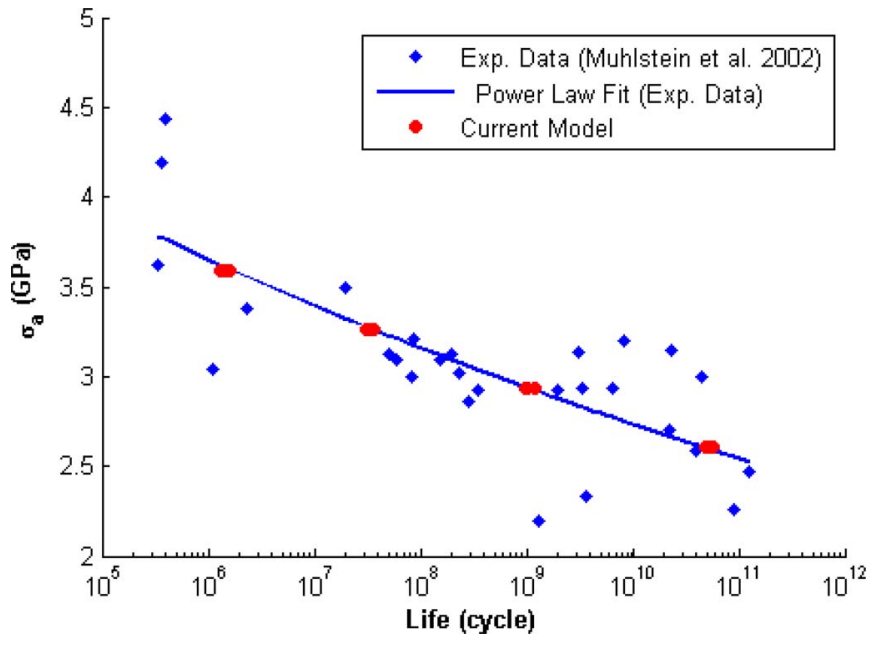

Fig. 21. Comparison of the S-N data obtained for the silicon MEMS specimens under the cyclic axial loading using the current model and the experimental curve.

2) normal distribution of resistance stress with a variation of $10 \%$ about the average value of $1334 \mathrm{MPa}$; and 3) introduction of the internal voids in the specimens. In order to observe the effects of the internal voids, they are distributed randomly in the left one-forth of the beams, i.e., in the maximum distance of $1 / 4$ beam length from the fixed end since there is a nonuniform stress distribution in the bending problem.

Fig. 18, also, shows a comparison between the values of the maximum tensile stress at the first loading cycle (no damage accumulated yet) in the 31 specimens obtained using the homogeneous material properties, the normal distribution of elastic modulus, and the internal voids. This figure does not show the maximum stress values for the normal distribution of resistance stress since they are exactly similar to the values obtained in the homogeneous specimens, as previously mentioned. Introducing inhomogeneity of elastic modulus and internal voids causes the increase in the maximum stress values in most of the specimens, as a conclusion of local stress concentrations. The average value of 308.7 MPa for the homogeneous specimens increases to 317.1 MPa in the presence of inhomogeneous elastic modulus and to $310 \mathrm{MPa}$ with introduction of the internal voids.

The Weibull plots of the initiation and total lives of the 31 specimens obtained using the homogeneous condition and three additional sources of randomness previously mentioned

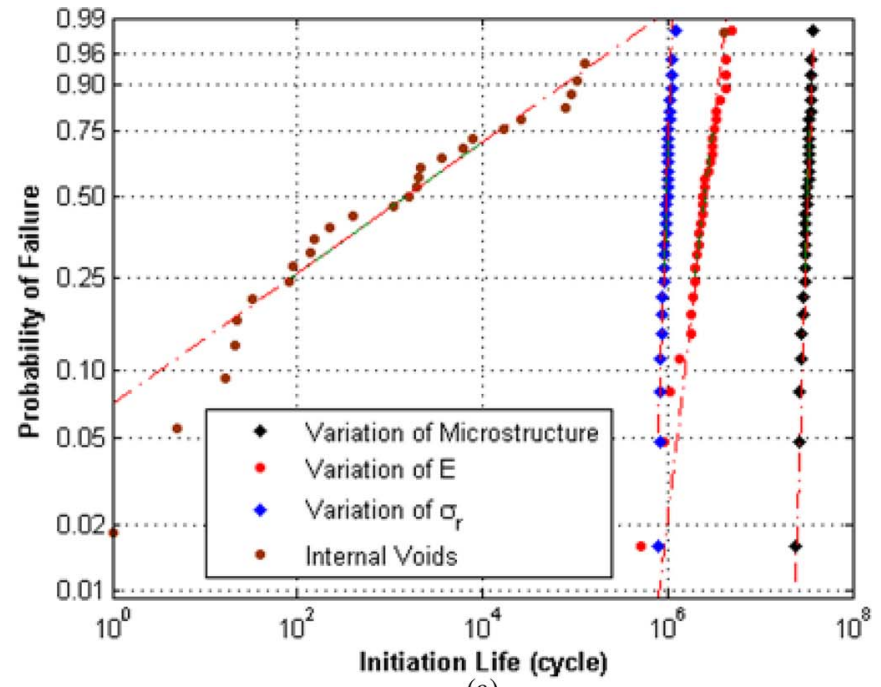

(a)

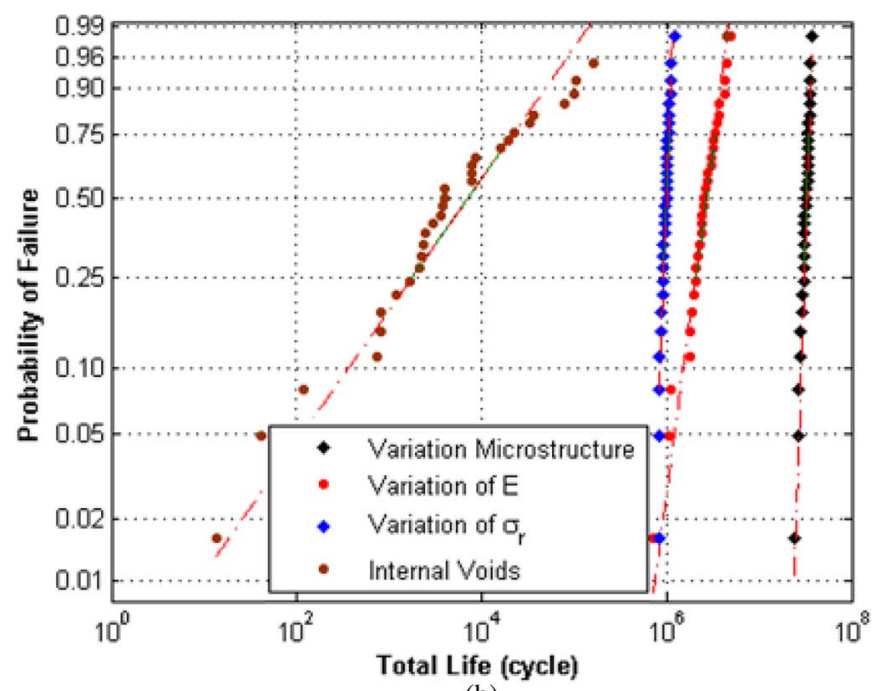

(b)

Fig. 22. Comparison of the Weibull distributions of (a) initiation lives, (b) total lives of the 31 silicon MEMS specimens under the cyclic axial loading for cases of the same material properties, normal distribution of elastic modulus, normal distribution of resistance stress, and the internal voids.

are shown in Fig. 20(a) and (b), respectively. Table IV lists the Weibull slopes and strengths obtained for different conditions. As expected, introduction of the inhomogeneous material properties (variation of $E$ and $\sigma_{\mathrm{r}}$ ) and internal voids increases the scatter of initiation and total lives of the 31 specimens, because now there are additional sources for randomness in the 
TABLE V

Weibull Slopes and Strengths Obtained For the Si Specimens Under the CyCliC AXIAL LOADING FOR THE DIFFERENT SIMULATION CONDITIONS

\begin{tabular}{|l|c|c|c|c|}
\hline \multirow{2}{*}{ Simulation Condition } & \multicolumn{2}{|c|}{ Initiation life } & \multicolumn{2}{c|}{ Total life } \\
\cline { 2 - 5 } & Weibull Slope "e" & $\begin{array}{c}\text { Weibull } \\
\text { Strength } \\
\text { (cycles) }\end{array}$ & Weibull Slope "e" & $\begin{array}{c}\text { Weibull } \\
\text { Strength } \\
\text { (cycles) }\end{array}$ \\
\hline Homogeneous & 12.82 & $3.33 \mathrm{e} 7$ & 12.67 & $3.34 \mathrm{e} 7$ \\
\hline $\begin{array}{l}\text { Variation of elastic } \\
\text { modulus }(E)\end{array}$ & 2.77 & $2.92 \mathrm{e} 6$ & 2.98 & $3.04 \mathrm{e} 6$ \\
\hline $\begin{array}{l}\text { Variation of resistance } \\
\text { stress }\left(\sigma_{r}\right)\end{array}$ & 10.84 & $1.02 \mathrm{e} 6$ & 11.07 & $1.02 \mathrm{e} 6$ \\
\hline One internal void & 0.28 & $6.55 \mathrm{e} 3$ & 0.38 & $1.84 \mathrm{e} 4$ \\
\hline
\end{tabular}

specimens than just the topological disorders. In addition, the variation of the resistance stress has a more significant effect on the fatigue life than the variation of the elastic modulus, because its direct influence in the damage evolution rate equation (6), as explained before. Variation of the resistance stress and introduction the internal voids reduces both initiation and total lives. In addition, the internal voids have less effect on the fatigue lives in the bending case than in the uniaxial problem considered in the previous section. Since there is a nonuniform stress field in the bending loading, the effect of the internal voids is more dependent on their location. As they are closer to the high-stress zones (corners close to the fixed end), they have larger effect on the fatigue life.

\section{Silicon TENSILE MEMS SPECIMENS}

In order to investigate the applicability of the fatigue damage model for other materials, in this section, we apply the fatigue damage model to silicon MEMS specimens. For this purpose, the specimens generated in Section VI are used; however, instead of using the material properties of $\mathrm{Ni}$ calculated in Section V, S-N data obtained by Muhlstein et al. [16] for silicon thin films under the fully reversed tension-compression loading is used to extract material properties of $\mathrm{Si}$ required for the fatigue damage model. Fig. 21 shows Muhlstein et al. [16] S-N data and power law fitted to the results. Using the approach explained in Section $\mathrm{V}$, these properties are calculated for silicon

$$
m=33.33 \sigma_{\mathrm{r}}=M_{0}=6068 \mathrm{MPa} .
$$

Using these material properties and the fatigue damage model, S-N data are obtained for four of the previously generated specimens under the cyclic axial loading. Fig. 21 shows the experimental data and the fatigue lives obtained using the current model. As illustrated, there is a good agreement between the results.

Now, effects of material imperfections on the fatigue lives of silicon MEMS specimens are studied, using the four different sources of randomness introduced in the previous sections. These include the following: 1) topological disorder using the 31 different domains previously generated; 2) normal distribution of elastic modulus with a variation of $10 \%$ about the average value of $163 \mathrm{GPa} ; 3$ ) normal distribution of resistance stress with a variation of $10 \%$ about the average value of $6068 \mathrm{MPa}$; and 4) introduction of the internal voids in the specimens as explained in Section VI-C. The Weibull plots of the initiation and total lives of the 31 specimens under the fully reversed tension-compression loading obtained using the four sources of randomness previously mentioned are shown in Fig. 22(a) and (b), respectively. In addition, Weibull slopes and strengths obtained for different conditions are listed in Table V. Again, introduction of the inhomogeneous material properties (variation of $E$ and $\sigma_{\mathrm{r}}$ ) and internal voids reduces the initiation and total lives and increases their scatter, because in these cases there are more sources of randomness in the specimens than just the topological disorders. There is a larger reduction in fatigue lives using the variation of resistance stress than using the variation of elastic modulus, which is explained in Section VI. In addition, the significant effect of the internal voids on the fatigue lives, and their scatter can be easily seen. Comparing Sections VI-VIII, it can be observed that the current model works well for both $\mathrm{Si}$ and $\mathrm{Ni}$ specimens.

\section{CONCLUSION}

In this paper, a new fatigue model based on the damage mechanics approach and Voronoi FEM was developed to study fatigue lives of MEMS devices and their scatter caused by the topological randomness and inhomogeneous material properties. The model is able to consider both crack initiation and propagation stages. Here, four different sources of randomness are considered: 1) microstructural topology; 2) the normal distribution of elastic modulus; 3 ) the normal distribution of resistance stress $\left(\sigma_{\mathrm{r}}\right)$; and 4$)$ the internal voids. Thirty-one MEMS specimens were simulated under cyclic axial and bending loading, and it was shown that the different stress gradients resulted by the different type of loading can affect the fatigue life. Since there is a nonuniform stress field in the bending loading, effect of microstructural distribution is more significant in the bending than axial loading. It was observed that the values of the maximum tensile stress varied between the different domains due to the effect of the microstructural topology, but their average value agreed well with the theoretical applied stress. The fatigue lives predicted are in good agreement with the experimental S-N curves of $\mathrm{Ni}$ and $\mathrm{Si}$ MEMS specimens. Again, due to the linear stress gradient existing in the bending case, the fatigue lives of specimens are generally higher than the ones obtained for the axial loading. Applying inhomogeneous material properties and internal voids to the specimens created local stress concentration and consequently changed the crack 
growth path. In addition, nonuniform resistance stress and internal voids reduced the fatigue lives and increased their scatter.

\section{REFERENCES}

[1] K. H. L. Chau and R. E. Sulouff, "Technology for the high-volume manufacturing of integrated surface-micromachined accelerometer products," Microelectron. J., vol. 29, no. 9, pp. 579-586, Sep. 1998.

[2] D. R. Sparks, S. R. Zarabadi, J. D. Johnson, Q. Jiang, M. Chia, O. Larsen, W. Higdon, and P. Castillo-Borelley, "A CMOS integrated surface micromachined angular rate sensor: It's automotive applications," in Proc. Int. Conf. Solid-State Sens., Actuators, 1997, vol. 2, pp. 851-854.

[3] C. L. Goldsmith, D. I. Forehand, Z. Peng, J. C. M. Hwang, and J. L. Ebel, "High-cycle life testing of RF MEMS switches," in IEEE MTT-S Int. Microw. Symp. Dig., 2007, pp. 1805-1808.

[4] S. B. Brown, W. Van Arsdell, and C. L. Muhlstein, "Materials reliability in MEMS devices," in Proc. Int. Conf. Solid-State Sens., Actuators Transducers, 1997, pp. 591-593.

[5] C. L. Muhlstein, S. B. Brown, and R. O. Ritchie, "High-cycle fatigue of polycrystalline silicon thin films in laboratory air," in Proc. Mater. Res. Soc. Symp., 2001, vol. 657, pp. EE 581-EE 586.

[6] H. Kahn, R. Ballarini, R. L. Mullen, and A. H. Heuer, "Electrostatically actuated failure of microfabricated polysilicon fracture mechanics specimens," Proc. R. Soc. London, vol. 455, no. 1990, pp. 3807-3823, Oct. 1999.

[7] H. Kapels, R. Aigner, and J. Binder, "Fracture strength and fatigue of polysilicon determined by a novel thermal actuator," IEEE Trans. Electron Devices, vol. 47, no. 7, pp. 1522-1528, Jul. 2000.

[8] J. A. Connally and S. B. Brown, "Micromechanical fatigue testing," Exp. Mech., vol. 33, no. 2, pp. 81-90, Jun. 1993.

[9] K. Minoshima, S. Inoue, T. Terada, and K. Komai, "Influence of specimen size and sub-micron notch on the fracture behavior of single crystal silicon microelements and nanoscopic AFM damage evaluation," in Proc. Mater. Res. Soc. Symp., 1999, vol. 546, pp. 15-19.

[10] X. Y. Ye, Z. Y. Zhou, Y. Yang, Z. H. Zhang, and J. Yao, "Determination of the mechanical properties of microstructures," Sens. Actuators A, Phys., vol. 54, no. 1-3, pp. 750-754, Jun. 1996.

[11] T. Tsuchiya, O. Tabata, J. Sakata, and Y. Taga, "Specimen size effect on tensile strength of surface micromachined polycrystalline silicon thin films," in Proc. IEEE 10th Annu. Int. Workshop Micro Electro Mech. Syst., 1997, pp. 529-534.

[12] G. K. Fedder and R. D. Blanton, "Characterization and reliability of CMOS microstructures,” Proc. SPIE, vol. 3880, pp. 132-239, Aug. 1999.

[13] J. Bagdahn and W. N. Sharpe, "Fatigue of polycrystalline silicon under long-term cyclic loading," Sens. Actuators A, Phys., vol. 103, no. 1/2, pp. 9-15, Jan. 2003.

[14] W. N. Sharpe and J. Bagdahn, "Fatigue testing of polysilicon-A review," Mech. Mater., vol. 36, no. 1/2, pp. 3-11, Jan./Feb. 2003.

[15] H. Kahn, R. Ballarini, and A. H. Heuer, "Dynamic fatigue of silicon," Curr. Opin. Solid State Mater. Sci., vol. 8, no. 1, pp. 71-76, Jan. 2004.

[16] C. L. Muhlstein, E. A. Stach, and R. O. Ritchie, "A reaction-layer mechanism for the delayed failure of micron-scale polycrystalline silicon structural films subjected to high-cycle fatigue loading," Acta Mater., vol. 50, no. 14, pp. 3579-3595, 2002.

[17] J. Mohr, P. Bley, M. Strohrmann, and U. Wallrabe, "Microactuators fabricated by the LIGA process," J. Micromech. Microeng., vol. 2, no. 4, pp. 234-241, Dec. 1992.

[18] J. Dual, E. Mazza, G. Schiltges, and D. Schlums, "Mechanical properties of microstructures: Experiments and theory," Proc. SPIE, vol. 3225, pp. 12-22, 1997.

[19] T. E. Buchheit, B. L. Boyce, and G. W. Wellman, "The role of microstructure in MEMS deformation and failure," in Proc. IMECE, 2002, pp. 559-566.

[20] J. Aktaa, J. T. Reszat, M. Walter, K. Bade, and K. J. Hemker, "High cycle fatigue and fracture behavior of LIGA nickel," Scripta Mater., vol. 52, no. 12 , pp. 1217-1221, Jun. 2005.

[21] S. M. Allameh, J. Lou, F. Kavishe, T. E. Buchheit, and W. O. Soboyejo, "An investigation of fatigue in LIGA Ni MEMS thin films," Mater. Sci. Eng. A, vol. 371, no. 1/2, pp. 256-266, Apr. 2004.

[22] B. L. Boyce, J. R. Michael, and P. G. Kotula, "Fatigue of metallic microdevices and the role of fatigue-induced surface oxides," Acta Mater., vol. 52, no. 6, pp. 1609-1619, Apr. 2004.

[23] Y. Yang, B. I. Imasogie, S. M. Allameh, B. Boyce, K. Lian, J. Lou, and W. O. Soboyejo, "Mechanisms of fatigue in LIGA Ni MEMS thin films," Mater. Sci. Eng. A, vol. 444, no. 1/2, pp. 39-50, Jan. 2007.
[24] K. J. Miller, "A historical perspective of the important parameters of metal fatigue; and problems for the next century," in Proc. 7th Int. Fatigue Congr., 1999, pp. 15-39.

[25] O. Ito and E. R. Fuller, "Computer modelling of anisotropic grain microstructure in two dimensions," Acta Metall. Mater., vol. 41, no. 1, pp. 191-198, 1993.

[26] P. D. Zavattieri, "Computational modeling for bridging size scales in the failure of solids," Ph.D. dissertation, Purdue Univ., West Lafayette, IN, 2000.

[27] P. D. Zavattieri and H. D. Espinosa, "Grain level analysis of crack initiation and propagation in brittle materials," Acta Mater, vol. 49, no. 20, pp. 4291-4311, Dec. 2001.

[28] T. S. Slack, F. Sadeghi, and D. Peroulis, "A phenomenological discrete brittle damage-mechanics model for fatigue of MEMS devices with application to LIGA Ni," J. Microelectromech. Syst., vol. 18, no. 1, pp. 119-128, Feb. 2009.

[29] L. M. Kachanov, "Time of the rupture process under creep conditions," Izv Akad Nauk SSR, Otd Tekh Nauk, vol. 8, pp. 26-31, 1958.

[30] Y. N. Robotnov, Creep Problems in Structural Mechanics. Amsterdam, The Netherlands: North Holland, 1969.

[31] J. L. Chaboche, "Continuum damage mechanics: Part I-General concepts," Trans. ASME, J. Appl. Mech., vol. 55, no. 1, pp. 59-64, 1988.

[32] I. R. Memon, X. Zhang, and D. Cui, "Fatigue life prediction of 3-D problems by damage mechanics with two-block loading," Int. J. Fatigue, vol. 24, no. 1, pp. 29-37, Jan. 2002.

[33] B. Jalalahmadi and F. Sadeghi, "A Voronoi finite element study of fatigue life scatter in rolling contacts," J. Tribol., vol. 131, no. 2, pp. 022 203-1022 203-15, Apr. 2009.

[34] A. Okabe and B. Boots, Spatial Tessellations: Concepts and Applications of Voronoi Diagrams. New York: Wiley, 1992.

[35] J. Moller, Lectures Notes on Random Voronoi Tessellations. Berlin, Germany: Springer-Verlag, 1994.

[36] J. Lemaitre, A Course on Damage Mechanics. Berlin, Germany: Springer-Verlag, 1992.

[37] J. L. Chaboche and P. M. Lesne, "A non-linear continuous fatigue damage model," Fatigue Fract. Eng. Mater. Struct., vol. 11, no. 1, pp. 1-17, 1988.

[38] Y. C. Xiao, S. Li, and Z. Gao, "A continuum damage mechanics model for high cycle fatigue," Int. J. Fatigue, vol. 20, no. 7, pp. 503-508, Aug. 1998.

[39] I. R. Memon, D. Cui, and X. Zhang, "Fatigue life prediction of 3-D problems by damage mechanics-Finite element additional load method," in Proc. 7th Int. Fatigue Conf., 1999, pp. 827-832.

[40] V. V. Bolotin, Mechanics of Fatigue. Boca Raton, FL: CRC Press, 1999.

[41] A. F. Grandt, Fundamentals of Structural Integrity. Hoboken, NJ: Wiley, 2004.

[42] W. Weibull, "A statistical distribution function of wide applicability," Trans. ASME, J. Appl. Mech., vol. 18, no. 3, pp. 293-297, 1951.

[43] A. Papoulis and S. U. Pillai, Probability, Random Variables and Stochastic Processes. New York: McGraw-Hill, 2002.

[44] J. A. Bannantine, J. J. Comer, and J. L. Handrock, Fundamentals of Metal Fatigue Analysis. Englewood Cliffs, NJ: Prentice-Hall, 1990.

[45] R. I. Stephens, A. Fatemi, R. R. Stephens, and H. O. Fuchs, Metal Fatigue in Engineering. New York: Wiley, 2000.

[46] N. E. Dowling, Mechanical Behavior of Materials. Englewood Cliffs, NJ: Prentice-Hall, 1999.

[47] J. E. Shigley, C. R. Mischke, and R. G. Budynas, Mechanical Engineering Design. New York: McGraw-Hill, 2004.

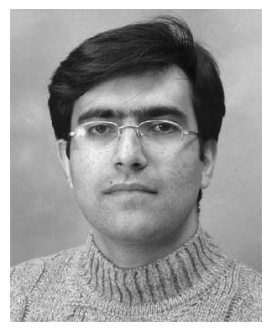

Behrooz Jalalahmadi received the B.S. and M.S. degrees in mechanical engineering from Sharif University of Technology, Tehran, Iran, in 2004 and 2006, respectively.

Since February 2007, he has been a Ph.D. Research Assistant in the School of Mechanical Engineering, Purdue University, West Lafayette, IN. 


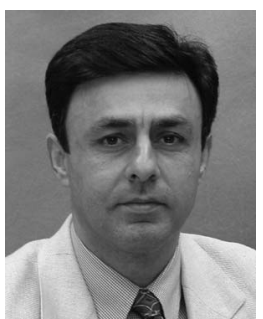

Farshid Sadeghi received the M.S. degree in mechanical engineering from the University of Tennessee in 1981 and the Ph.D. degree in mechanical engineering from North Carolina State University in 1985 .

He is currently a Professor of mechanical engineering at Purdue University, West Lafayette, IN. His research interests include tribology, fatigue, fracture surface science, and microelectromechanical sensors for tribological applications. He has authored or coauthored more than 90 archival publications in leading international journals and has given over 250 presentations at various conferences, industries, and governmental agencies.

Prof. Sadeghi is a Fellow of the American Society of Mechanical Engineers (ASME) and the Society of Tribologists and Lubrication Engineers. He has received numerous awards from the ASME and Society of Tribologists and Lubrication Engineers, and has graduated 55 Ph.D. and M.S. students, currently serving as the chairman of $12 \mathrm{Ph} . \mathrm{D}$. students and one M.S. student. He has chaired, cochaired, and/or organized over 75 sessions at international conferences and served as the Chairman of the 2000 ASME Tribology Conference in Seattle, WA.

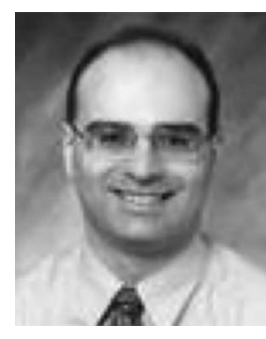

Dimitrios Peroulis received the Ph.D. degree in electrical engineering from the University of Michigan, Ann Arbor, in 2003.

$\mathrm{He}$ has been with Purdue University, West Lafayette, IN, since August 2003, where he is currently leading a group of $15 \mathrm{Ph} . \mathrm{D}$. students in a variety of research projects in the areas of MEMS for RF, sensing and power harvesting applications, as well as RFID sensors for the health monitoring of sensitive equipment. He has nine years experience in his field of expertise and he has led a variety of projects funded by the U.S. Air Force, Army, and Defense Advanced Research Projects Agency (DARPA) in these areas. He is currently leading two DARPA projects at Purdue focusing on: 1) very-high-quality (Q>1000) RF tunable filters (Evanescent Filter Cavities for Analog Spectral Processing) and 2) developing sophisticated models for understanding the failure mechanisms of MEMS devices (University Center on MEMS/NEMS S\&T Fundamentals Program). In addition, he is leading an Air Force project on RFID MEMS sensors and two National Science Foundation projects on wireless networks. $\mathrm{He}$ has over 40 refereed journal and conference publications in the areas of microwave integrated circuits and antennas.

Dr. Peroulis is a member of the Center of Wireless Systems and Applications and the Birck Nanotechnology Center at Purdue University. He has also won six outstanding teacher awards at Purdue University. He received two student paper awards at the 2001 and 2002 International Microwave Symposiums. 